\title{
Mutated nucleophosmin 1 as immunotherapy target in acute myeloid leukemia
}

\author{
Dyantha I. van der Lee, ${ }^{1}$ Rogier M. Reijmers, ${ }^{1}$ Maria W. Honders, ${ }^{1}$ Renate S. Hagedoorn, ${ }^{1}$ Rob C.M. de Jong, ${ }^{1}$ Michel G.D. Kester, ${ }^{1}$ \\ Dirk M. van der Steen, ${ }^{1}$ Arnoud H. de Ru, ${ }^{2}$ Christiaan Kweekel, ${ }^{1}$ Helena M. Bijen, ${ }^{1}$ Inge Jedema, ${ }^{1}$ Hendrik Veelken, ${ }^{1}$ \\ Peter A. van Veelen, ${ }^{2}$ Mirjam H.M. Heemskerk, ${ }^{1}$ J.H. Frederik Falkenburg, ${ }^{1}$ and Marieke Griffioen ${ }^{1}$ \\ 1Department of Hematology, and 'Center for Proteomics and Metabolomics, Leiden University Medical Center, Leiden, Netherlands.
}

\begin{abstract}
The most frequent subtype of acute myeloid leukemia (AML) is defined by mutations in the nucleophosmin 1 (NPM1) gene. Mutated NPM1 ( $N$ NPM1) is an attractive target for immunotherapy, since it is an essential driver gene and 4 bp frameshift insertions occur in the same hotspot in 30\%-35\% of AMLs, resulting in a C-terminal alternative reading frame of 11 aa. By searching the HLA class I ligandome of primary AMLs, we identified multiple $\triangle N P M 1$-derived peptides. For one of these peptides, HLA-A*02:01-binding CLAVEEVSL, we searched for specific T cells in healthy individuals using peptide-HLA tetramers. Tetramer-positive CD8 ${ }^{+} \mathrm{T}$ cells were isolated and analyzed for reactivity against primary AMLs. From one clone with superior antitumor reactivity, we isolated the T cell receptor (TCR) and demonstrated specific recognition and lysis of HLA-A* 02:01-positive $\triangle$ NPM1 AML after retroviral transfer to CD8 ${ }^{+}$and CD4 ${ }^{+}$T cells. Antitumor efficacy of TCR-transduced T cells was confirmed in immunodeficient mice engrafted with a human AML cell line expressing $\triangle N P M 1$. In conclusion, the data show that $\triangle$ NPM1-derived peptides are presented on AML and that CLAVEEVSL is a neoantigen that can be efficiently targeted on AML by $\triangle$ NPM1 TCR gene transfer. Immunotherapy targeting $\triangle N P M 1$ may therefore contribute to treatment of AML.
\end{abstract}

\section{Introduction}

Acute myeloid leukemia (AML) is characterized by accumulation of malignant myeloid precursor cells that are arrested in differentiation in the bone marrow. Standard therapy of AML consists of induction chemotherapy followed by intensive consolidation chemotherapy or high-dose therapy in combination with autologous or allogeneic hematopoietic stem cell transplantation (alloSCT) (1, 2). Although most patients respond to therapy and achieve complete remission, relapses occur frequently. Patients with relapsed or refractory AML after intensive chemotherapy or alloSCT have an extremely poor prognosis, and there is a strong need for new and effective therapies to treat these patients.

Molecular characterization of AML using whole-genome and exome sequencing demonstrated that AML has a low mutational load with an average of 10-13 coding mutations per patient (3-5). In contrast to what occurs in most other cancer types, somatic abnormalities in AML often occur in the same genes $(3,6)$ and antigens arising from hotspot mutations in these genes are therefore attractive targets for immunotherapy. Nucleophosmin 1 (NPM1) is a driver gene that is mutated in $30 \%-35 \%$ of AMLs $(3,6)$. Although AMLs are often heterogeneous mixtures of different leu-

\section{Related Commentary: p. 506}

Authorship note: JHFF and MG are co-senior authors. Conflict of interest: JHFF and MG are inventors on a pending patent for the nonoptimized and optimized TRAV and TRBV sequences of TCRs for mutated NPM1 as well as cells containing these TCR sequences (no. 2019156).

License: Copyright 2019, American Society for Clinical Investigation.

Submitted: September 15, 2017; Accepted: November 6, 2018.

Reference information: J Clin Invest. 2019;129(2):774-785.

https://doi.org/10.1172/JCI97482. kemic subclones $(3,7)$, mutations in NPM1 are initiating mutations that are present in all leukemic cells, illustrating that these mutations are clonal and essential for malignant transformation early in leukemogenesis. Patients with mutated NPM1 ( $\mathrm{NPM} 1)$ carry a characteristic $4 \mathrm{bp}$ frameshift insertion in exon 12 of the gene. The resulting $\triangle \mathrm{NPM} 1$ protein is 4 aa longer than the WT counterpart, and its C-terminal 11 aa are translated in an alternative reading frame (CLAVEEVSLRK) (8). The $4 \mathrm{bp}$ frameshift insertions occur at restricted positions in the coding sequence and, although the exact 4 bp sequence can differ, the majority of mutations encode the same 11 aa alternative reading frame.

Immunotherapy by in vivo vaccination or adoptive transfer of $\mathrm{T}$ cells that are produced in vitro can be very effective. In particular, chimeric antigen receptor (CAR) and $\mathrm{T}$ cell receptor (TCR) gene therapy targeting lineage-restricted or cancer-associated antigens have shown promising results (9-11). However, due to (low) antigen expression in healthy tissues, antitumor immunity can be accompanied by severe toxicity $(9,10,12)$. In contrast with antigens encoded by unmutated genes, neoantigens arise from tumor-specific mutations and their formation and expression are restricted to malignant cells (13-15). The majority of neoantigens, however, are encoded by patient-specific passenger mutations that can be lost as a result of immune editing and lead to tumor evasion (16). Immune escape for neoantigens created by driver mutations is less likely, since tumor cells need to express the driver gene in order to retain their malignant phenotype (13). Since $\triangle$ NPM1 is a driver mutation that occurs in $30 \%-35 \%$ of AMLs, its C-terminal 11 aa alternative reading frame may be an ideal target for immunotherapy.

In this study, we searched in the HLA class I ligandome of primary AMLs and identified multiple peptides from the alternative reading frame of $\triangle \mathrm{NPM} 1$. For one of these peptides, the 
Table 1. $\triangle$ NPM1 peptides in the HLA class I ligandome of primary AMLs

\begin{tabular}{|c|c|c|c|c|c|c|}
\hline Patient & HLA class I & $\Delta \mathrm{NPM} 1^{\mathrm{A}}$ & Karyotype & Blasts $^{\mathrm{B}}$ & Eluted peptide & No. spectra ${ }^{c}$ \\
\hline AML10197 & $\begin{array}{c}A^{*} 01: 01 A^{*} 02: 01 \\
B^{*} 08: 01 B^{*} 44: 03 \\
C^{*} 07: 01 C^{*} 16: 01\end{array}$ & + & $46, X X$ & $98 \%$ & CLAVEEVSL & 11,232 \\
\hline AML3361 & $\begin{array}{c}A^{*} 02: 01 A^{*} 11 \\
B^{*} 13 B^{*} 35 \\
C^{*} 04 C^{*} 06\end{array}$ & + & $46, X X$ & $79 \%$ & $\begin{array}{c}\text { CLAVEEVSL } \\
\text { AVEEVSLRK } \\
\text { VEEVSLRK }\end{array}$ & 7,992 \\
\hline AML6395 & $\begin{array}{l}A^{*} 02: 01 A^{*} 24: 03 \\
B^{*} 38: 01 B^{*} 51: 01 \\
C^{*} 02: 02 C^{*} 12: 03\end{array}$ & + & $46, X Y$ & $80 \%$ & - & $3,915^{0}$ \\
\hline AML9448 & $\begin{array}{l}A^{*} 03: 01 A^{*} 32: 01 \\
B^{*} 07: 02 B^{*} 08: 01 \\
C^{*} 07: 01 C^{*} 07: 10\end{array}$ & + & $46, X X$ & $77 \%$ & $\begin{array}{c}\text { CLAVEEVSLRK } \\
\text { AVEEVSLRK }\end{array}$ & 10,352 \\
\hline AML5444 & $\begin{array}{c}A^{*} 03: 01 \\
B^{*} 07: 02 B^{*} 35: 01 \\
C^{*} 04: 01 C^{*} 07: 02\end{array}$ & + & $46, X X$ & $55 \%$ & AVEEVSLRK & 6,209 \\
\hline AML5518 & $\begin{array}{c}A^{*} 01: 01 A^{*} 24: 02 \\
B^{*} 35: 03 B^{*} 44: 03 \\
C^{*} 04: 01 C^{*} 16: 01\end{array}$ & + & $46, X X$ & $95 \%$ & $\begin{array}{c}\text { AVEEVSLRK } \\
\text { AVEEVSLR }\end{array}$ & 8,479 \\
\hline AML6498 & $\begin{array}{c}A^{*} 11: 01 A^{*} 68: 01 \\
B^{*} 35: 01 B^{*} 35: 03 \\
C^{*} 04: 01\end{array}$ & + & $46, X X$ & $94 \%$ & $\begin{array}{c}\text { CLAVEEVSLRK } \\
\text { AVEEVSLRK }\end{array}$ & 12,233 \\
\hline AML4443 & $\begin{array}{l}A^{*} 01: 01 \\
B^{*} 08: 01 \\
C^{*} 07: 01\end{array}$ & + & $46, X X$ & $82 \%$ & AVEEVSLRK & 4,037 \\
\hline AML1775 & $\begin{array}{c}A^{*} 24 A^{*} 02: 01 \\
B^{*} 51 B^{*} 40: 01 \\
C^{*} 10 C^{*} 03\end{array}$ & - & $\begin{array}{l}\text { 46, XY, inv(16) } \\
\text { (p13q22) }\end{array}$ & $89 \%$ & - & $524^{\circ}$ \\
\hline AML2250 & $\begin{array}{c}A^{*} 02: 01 A^{*} 01: 01 \\
B^{*} 62 B^{*} 15: 01 \\
C^{*} 10 C^{*} 03\end{array}$ & - & $46, X Y$ & $95 \%$ & - & $4,286^{\circ}$ \\
\hline AML1143 & $\begin{array}{l}A^{*} 02: 01 A^{*} 03: 01 \\
B^{*} 07: 02 B^{*} 35: 01 \\
C^{*} 04: 01 C^{*} 07: 02\end{array}$ & - & $46, X Y$ & $90 \%$ & - & 5,571 \\
\hline AML3009 & $\begin{array}{c}A^{*} 11 A^{*} 02: 01 \\
B^{*} 15: 01 B^{*} 07: 02 \\
C^{*} 03 C^{*} 07\end{array}$ & - & $46, X Y$ & $70 \%$ & - & $4,466^{\circ}$ \\
\hline \multicolumn{7}{|c|}{$\begin{array}{l}{ }^{\mathrm{A}} \triangle \mathrm{NPM} 1 \text { are } 4 \text { bp insertions in exon } 12 \text { of NPM1 causing a frameshift at the } \mathrm{C} \text { terminus of the protein. } \\
{ }^{\mathrm{B} B} \text { last percentages in peripheral blood or bone marrow samples used for peptidome analysis. }{ }^{\mathrm{C}} \text { Number } \\
\text { of Mascot-identified unique } 8 \text { - to } 11 \text {-mer peptide sequences in the UniProt Homo Sapiens database with } \\
\text { MIS } \geq 35 \text {. }{ }^{D} \mathrm{AML} \text { samples for which peptide-HLA complexes were immunoprecipitated by BB7.2 (anti- } \\
H L A-A^{*} 02: 01 \text { ) antibody. For all other AML samples, W6/32 (anti-HLA class I) antibody was used. }\end{array}$} \\
\hline
\end{tabular}

ried chromosomal translocation inv(16) (p13q22), resulting in the CBFB-MYH11 fusion gene. Blast percentages in peripheral blood or bone marrow samples used for peptidome analysis ranged between $55 \%$ and $98 \%$.

The 4 bp hotspot insertion in exon 12 results in a $\triangle \mathrm{NPM} 1$ protein that is 4 aa longer than its WT counterpart, with 11 aa (CLAVEEVSLRK) at the C terminus translated in an alternative reading frame (Figure 1). From this $\triangle$ NPM1 protein, a sequence spanning $10 \mathrm{~N}$-terminal residues in the normal reading frame followed by the $11 \mathrm{C}$-terminal aa in the alternative reading frame (MTDQEAIQDLCLAVEEVSLRK) was used to search for matching peptides in the HLA class I ligandomes of the 12 primary AMLs. This search revealed two 8-mer peptides (VEEVSLRK and AVEEVSLR), two 9-mer peptides (CLAVEEVSL and AVEEVSLRK), and one 11-mer peptide (CLAVEEVSLRK) in $\triangle$ NPM1 AML, but not in WT NPM1 (WTNPM1) AML (Table 1). All 5 ligands as eluted from 7 AMLs were validated by comparing tandem mass spectra with synthetic peptides (Figure 2 and Supplemental Figure 1; supplemental material available online with this article; https://doi. org/10.1172/JCI97482DS1). Tandem mass spectra of the eluted CLAVEEVSL and CLAVEEVSLRK ligands were confirmed upon cysteinylation of the first residue of the synthetic peptide, indicating that cysteinylated variants of these peptides are presented on primary AMLs. Using NetMHCpan 3.0 (17), CLAVEEVSL was predicted to bind to HLA-A ${ }^{*} 02: 01$ and AVEEVSLRK and CLAVEEVSLRK to HLA-A ${ }^{*}$ 03:01 as well as HLA-A ${ }^{*} 11: 01$

HLA-A ${ }^{*}$ 02:01-binding peptide CLAVEEVSL, we demonstrated its relevance as a therapeutic neoantigen that can be efficiently targeted on AML by TCR gene transfer, indicating that $\triangle \mathrm{NPM} 1$ is a relevant target for immunotherapy of AML.

\section{Results}

$\triangle N P M 1$ peptides in the HLA class I ligandome of primary AMLs. To investigate whether $\triangle$ NPM1 peptides are processed and presented on AML, we immunoprecipitated HLA class I surface molecules from 12 primary AMLs, eluted the peptides from the binding groove, and analyzed the peptidome by tandem mass spectrometry (MS/MS). Table 1 shows HLA typing of these 12 AMLs as well as their mutational status for NPM1. Eight of the 12 AMLs were positive for $\triangle \mathrm{NPM} 1$ by routine diagnostics. All patients had normal karyotypes by cytogenetics except for $1 \mathrm{AML}$, which car-
(Supplemental Table 1), which was confirmed by appropriate peptide folding in the respective HLA class I monomers.

CLAVEEVSL as $\triangle N P M 1$-derived neoantigen. Since HLA$\mathrm{A}^{*} 02: 01$ is expressed in $50 \%$ of the White population, we selected CLAVEEVSL to explore its relevance as therapeutic neoantigen and searched for specific T cells in AML patients. Phycoerythrin-conjugated (PE-conjugated) peptide-HLA (pHLA) tetramers were produced for CLAVEEVSL ( $\triangle$ NPM1-CLA) and its cysteinylated variant $C^{*}$ LAVEEVSL ( $\triangle N P M 1-C^{*} L A$ ), and a mix of these tetramers was used to isolate specific $\mathrm{T}$ cells from PBMCs from 6 HLA-A ${ }^{*} 02: 01$-positive AML patients with $\triangle$ NPM1 who were in remission after chemotherapy. T cells binding to 1 or both pHLA tetramers were enriched by magnetic anti-PE beads, and single tetramer-positive $\mathrm{CD} 8^{+} \mathrm{T}$ cells were isolated by flow cytometry (Supplemental Table 2). A total of 41 tetramer-positive $\mathrm{CD} 8^{+}$ 


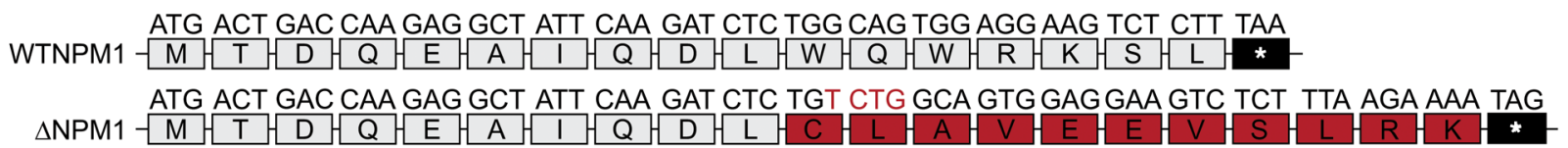

Figure 1. DNA and protein sequences for WTNPM1 and $\triangle$ NPM1. Nucleic and amino acid sequences are shown for WTNPM1 (upper) and $\triangle$ NPM1 (lower). Indicated is a TCTC insertion between c.863_864 in the coding sequence of NPM1, which is the most frequent frameshift mutation in the hotspot region. Translated aa sequences are shown until the termination sequence (stop, indicated by asterisks). As a consequence of the TCTC insertion, the $C$-terminal aa CLAVEEVSLRK of $\triangle$ NPM1 are translated in an alternative reading frame. WT and mutant aa are indicated in gray and red, respectively.

T cells were isolated from $34 \times 10^{6}$ PBMCs from 4 patients; of these, 5 clones from 3 patients expanded. None of these $5 \mathrm{~T}$ cell clones, however, stained with the $\triangle$ NPM1-CLA or $\triangle \mathrm{NPM1-C}{ }^{\star} \mathrm{LA}$ tetramer. In addition to direct $\mathrm{T}$ cell isolation, we also screened for tetramer-positive $\mathrm{T}$ cells after in vitro peptide stimulation, but failed to detect these T cells above background in any of the 4 patients analyzed (Supplemental Table 3 and Supplemental Figure 2). These data indicate that $\mathrm{T}$ cells for $\triangle \mathrm{NPM} 1$ did not exist at frequencies that could be detected in limited numbers of PBMCs, as available from AML patients in remission after chemotherapy. Since we and others previously demonstrated that tumor-specific $\mathrm{T}$ cells can be present at low frequencies in healthy individuals $(18,19)$, we followed the same strategy as described above and directly isolated tetramer-positive $\mathrm{T}$ cells from large numbers of PBMCs from 6 HLA-A ${ }^{*}$ 2:01-positive healthy individuals (Table 2). A variable number of 8 to 55 tetramer-positive $C D 8^{+} \mathrm{T}$ cells were isolated from $460-1970 \times 10^{6} \mathrm{PBMCs}$ from each individual. Of these cells, 31 clones from 5 individuals expanded and $13 \mathrm{~T}$ cell clones from 4 individuals were positive for the $\triangle$ NPM1-CLA tetramer. Of these 13 clones, $3 \mathrm{~T}$ cell clones also stained with the $\triangle$ NPM1-C* LA tetramer (Figure 3A).

To determine whether the 13 tetramer-positive CD8 clones were reactive against their target peptide, clones were tested for reactivity against $\mathrm{HLA}^{*} \mathrm{~A}^{*}$ 02:01-positive $\mathrm{T} 2$ cells exogenously loaded with CLAVEEVSL, the cysteinylated variant $C^{*}$ LAVEEVSL,

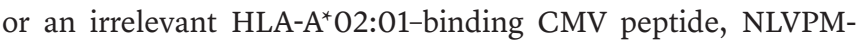
VATV. Of the $13 \triangle$ NPM1-CLA tetramer-positive clones, $2 \mathrm{~T}$ cell clones (1A2 and 4A8) showed specific reactivity against $\mathrm{T} 2$ cells loaded with CLAVEEVSL, but not control peptide NLVPMVATV (Figure 3B). Clone 1A2 also showed recognition of $C^{*}$ LAVEEVSL. These results are in line with tetramer data and demonstrate that clone 1A2 recognizes uncysteinylated as well as cysteinylated $\triangle$ NPM1, whereas only uncysteinylated $\triangle$ NPM1 is recognized by clone $4 \mathrm{~A} 8$.

To investigate the antitumor potential of clones $1 \mathrm{~A} 2$ and $4 \mathrm{~A} 8, \mathrm{~T}$ cell reactivity was measured against $5 \mathrm{HLA}^{*} \mathrm{~A}^{*}$ 02:01-positive primary AMLs, including 3 samples with $\triangle$ NPM1 and 2 samples with WTNPM1. T cell clone 1A2 showed reactivity against all 3 AMLs with $\triangle N P M 1$, whereas clone $4 \mathrm{~A} 8$ showed reactivity against 2 of these samples (Figure 3C). Superior reactivity against AML by clone $1 \mathrm{~A} 2$ may be explained by its capacity to recognize cysteinylated $\triangle \mathrm{NPM} 1$ as identified on the surface of primary AML by MS. No T cell reactivity was observed against $\mathrm{HLA}^{*} \mathrm{~A}^{*} 02: 01-$ positive AML with WTNPM1 (Figure 3C). These data indicate that $\triangle$ NPM1 tetramer-positive T cells are present in healthy individuals and that a minority of these T cells are able to react to $\triangle$ NPM1positive primary AML.

TCR gene transfer to target $\triangle N P M 1$ on AML. Since $\triangle N P M 1$ is a driver mutation that occurs in $30 \%-35 \%$ of AMLs and HLA-A ${ }^{*} 02: 01$ is expressed in $50 \%$ of the White population, we considered CLAVEEVSL an attractive target for TCR gene transfer. Since primary AMLs were most strongly recognized by clone 1A2, mRNA was isolated from this clone and cDNA was generated to sequence the variable regions of the TCR $\alpha$ and $\beta$ chains for $\triangle$ NPM1. Codon-optimized gene sequences for TRAV12-2 and TRBV5-1 as expressed by clone 1A2 were synthesized and cloned into a modified MP71-TCR-flex retroviral vector (20). To facilitate preferential binding and expression of the TCR $\alpha$ and $\beta$ chains, the variable regions of the TCR were cloned in-frame with murine constant regions linked by a P2A sequence. The TCR for $\triangle$ NPM1 and, as a control, a TCR for HLA-A ${ }^{*} 02$ :01-binding CMV pp65 peptide NLVPMVATV were introduced into $\mathrm{CD}^{+}$and $\mathrm{CD} 4^{+} \mathrm{T}$ cells isolated from PBMCs from HLA-A ${ }^{*}$ 2: $: 01-$ positive healthy individuals (donors 1, 2, and 3). At day 6 after transduction, TCR-transduced $\mathrm{CD}^{+}$and $\mathrm{CD}^{+} \mathrm{T}$ cells were purified using an allophycocyanin (APC)-conjugated antibody against mouse TCR-C $\beta$ and magnetic anti-APC beads. Flow cytometry demonstrated specific binding of the $\triangle$ NPM1-CLA tetramer to $\mathrm{CD}^{+} \mathrm{T}$ cells transduced with the TCR for $\triangle \mathrm{NPM} 1$ (CD8ØNPM1), but not to $\mathrm{CD} 8^{+} \mathrm{T}$ cells transduced with the CMV-specific TCR (CD8ØCMV) (Figure 4A). Conversely, the CMV-NLV tetramer did not bind to $\mathrm{CD}^{+}{ }^{+} \mathrm{T}$ cells transduced with the TCR for $\triangle$ NPM1, whereas it clearly stained CD8 ${ }^{+}$

Table 2. Direct isolation of $\triangle$ NPM1-specific T cells from healthy individuals

\begin{tabular}{|c|c|c|c|c|c|c|}
\hline Donor & $\begin{array}{l}\text { PBMCA } \\
\left(\times 10^{6}\right)\end{array}$ & $\begin{array}{l}\text { Sorted } \\
T \text { cells }{ }^{B}\end{array}$ & $\begin{array}{l}\text { Growing } \\
\text { clones }\end{array}$ & $\begin{array}{c}\Delta \text { NPM1-CLA } \\
\text { tetramer }^{C}\end{array}$ & $\begin{array}{c}\Delta \text { NPM1- }^{*}{ }^{*} \text { LA } \\
\text { tetramer }^{D}\end{array}$ & $\begin{array}{c}\text { Reactive } \\
\text { clones }\end{array}$ \\
\hline 1 & 460 & 14 & 4 & 2 & 1 & 1 \\
\hline 2 & 700 & 8 & 6 & 4 & ND & 0 \\
\hline 3 & 970 & 20 & 7 & 3 & 0 & 0 \\
\hline 4 & 560 & 24 & 8 & 0 & 0 & - \\
\hline 5 & 545 & 13 & 0 & - & - & - \\
\hline 6 & 1970 & 55 & 6 & 4 & 2 & 1 \\
\hline
\end{tabular}

Andicated are numbers of PBMCs from HLA-A*02:01-positive healthy individuals that are used for T cell isolation. ${ }^{B}$ PBMCs were stained with anti-CD8-Alexa Fluor 700 and a mix of PE-conjugated pHLA tetramers for CLAVEEVSL and its cysteinylated variant, C* LAVEEVSL. Indicated are numbers of tetramer-positive $\mathrm{CD}^{+} \mathrm{T}$ cells that are sorted. ${ }^{\mathrm{C}}$ Number of growing $\mathrm{T}$ cell clones positive for the $\triangle$ NPM1-CLA tetramer. ${ }^{D}$ Number of growing $T$ cell clones positive for the $\triangle N P M 1-C^{*}$ LA tetramer. ND, not done. 

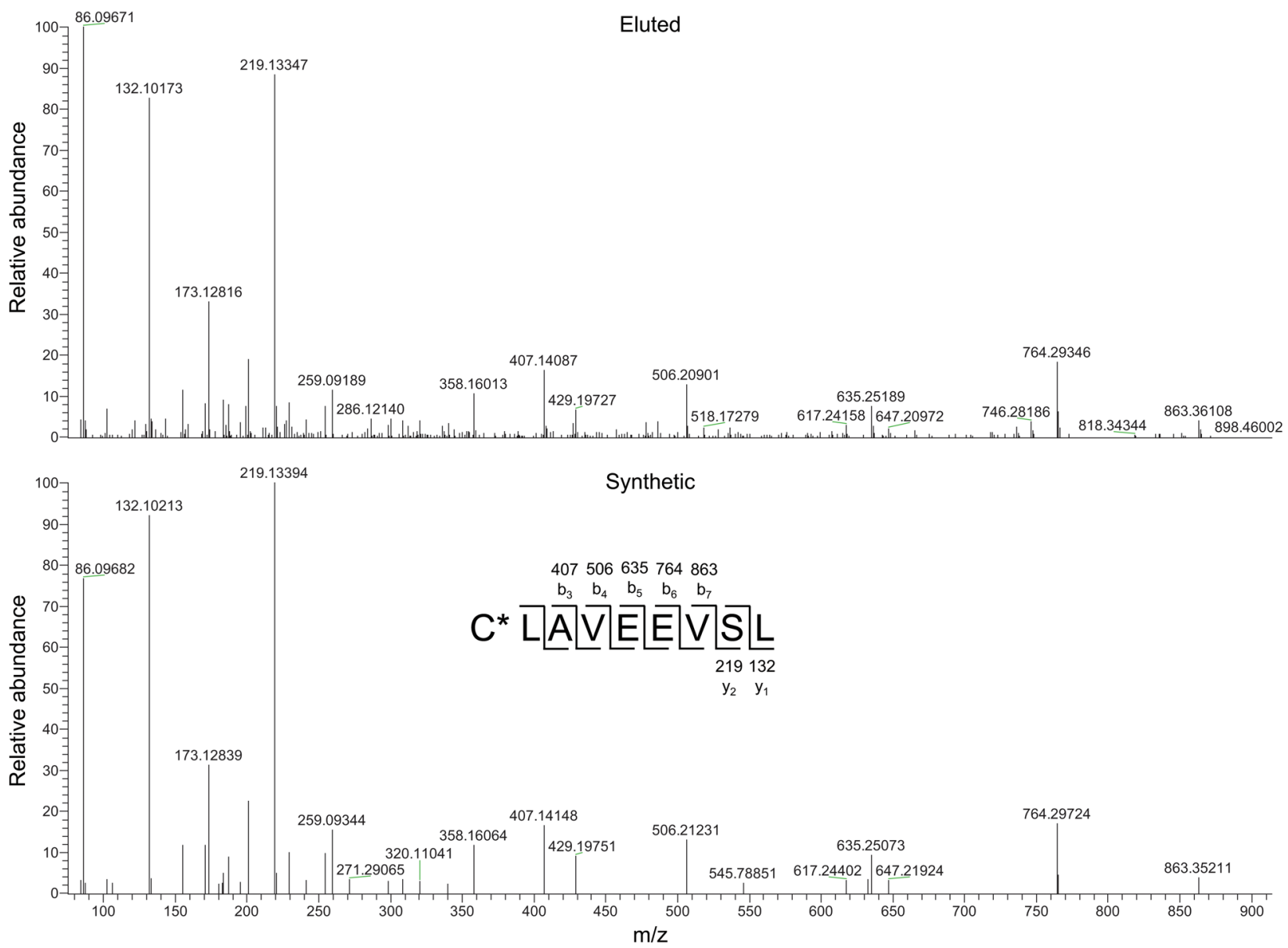

Figure 2. Validation of $C^{*}$ LAVEEVSL as peptide eluted from HLA-A*02:01-positive AML with $\triangle N P M 1 . C^{*} L A V E E V S L$ was validated as peptide eluted from HLA-A*02:01-positive AML with $\triangle N P M 1$ by comparing MS/MS between eluted peptides and synthetic peptide $C^{*}$ LAVEEVSL. Matching MS/MS are shown for an eluted peptide from AML10197 (upper panel) and synthetic peptide $C^{*}$ LAVEEVSL (lower panel). $C^{*}$, cysteinylation of the Cys residue.

T cells transduced with the CMV-specific TCR. For TCR-transduced $\mathrm{CD}^{+} \mathrm{T}$ cells (CD4ØNPM1 and CD4ØCMV), results were similar, indicating that the $\triangle$ NPM1-CLA tetramer binds to $\triangle$ NPM1 TCR-transduced $\mathrm{T}$ cells independently of the CD8 coreceptor. TCR-transduced $\mathrm{CD}^{+}$and $\mathrm{CD} 4^{+} \mathrm{T}$ cells were also stained with an antibody against mouse TCR-C $\beta$, and $\mathrm{CD} 8^{+}$and $\mathrm{CD} 4^{+} \mathrm{T}$ cells transduced with the TCR for $\triangle \mathrm{NPM} 1$ also showed specific binding to an antibody against human TCR-V $\beta 5.1$ (Supplemental Figure 3).

Next, we analyzed the functionality of $\mathrm{CD}^{+}$and $\mathrm{CD} 4^{+} \mathrm{T}$ cells transduced with the TCR for $\triangle \mathrm{NPM} 1$ and demonstrated specific release of IFN- $\gamma$ upon incubation with $\mathrm{HLA}^{*}{ }^{*}$ 02:01-positive T2 cells loaded with CLAVEEVSL, but not CMV peptide NLVPMVATV (Figure 4B). Specific release of IFN- $\gamma$ was also observed upon stimulation with HLA-A ${ }^{*} 2$ :01-positive and $\triangle$ NPM1-mutated AML cell line OCI-AML3, but not HLA-A02:01-positive WTNPM1 AML cell line OCI-AML2. Blocking experiments confirmed that recognition of OCI-AML3 by TCR-modified $\mathrm{CD} 8^{+}$and $\mathrm{CD} 4^{+}$ T cells was mediated by HLA class I (Figure 4C).

TCR-transduced $\mathrm{CD}^{+}$and $\mathrm{CD} 4^{+} \mathrm{T}$ cells were subsequently tested for reactivity against a panel of 13 HLA-A ${ }^{*}$ 22:01-positive primary AMLs, including 9 samples with $\triangle$ NPM1 and 4 samples with WTNPM1. Upon transduction with the TCR for $\triangle$ NPM1, $\mathrm{CD}^{+}$and $\mathrm{CD}^{+}{ }^{+} \mathrm{T}$ cells both showed recognition of all 9 AMLs with $\triangle$ NPM1, whereas no specific recognition of AML with WTNPM1 was observed (Figure 5). Despite variable expression of HLA-A ${ }^{*}$ 2:01 and costimulatory and adhesion molecules on leukemic cells (Supplemental Table 4), the TCR for $\triangle$ NPM1 was strongly reactive against all AML analyzed, except for AML10594, which has a low percentage of leukemic blasts (27\%). We also analyzed $\triangle$ NPM1 gene expression and variant allele frequencies using RNA-Seq data for these AMLs (Supplemental Table 5). RNA-Seq analysis revealed high gene expression and variant allele frequencies, thereby confirming strong and clonal expression of $\triangle \mathrm{NPM} 1$ in all AML cases tested.

$\mathrm{CD} 8^{+}$and $\mathrm{CD} 4^{+} \mathrm{T}$ cells transduced with the TCR for $\triangle \mathrm{NPM} 1$ lacked reactivity against $\mathrm{HLA}^{*} \mathrm{~A}^{*}$ 2:01-negative AML with $\triangle$ NPM1. There was also no reactivity against HLA-A ${ }^{*}$ 2:01-positive mature monocyte-derived DC and a panel of HLA-A ${ }^{*} 02: 01-$ positive EBV-LCL (Supplemental Figure 4), excluding production of a peptide resembling CLAVEEVSL by alternative translation of the WTNPM1 gene and off-target reactivity against a ubiquitous peptide presented by HLA-A ${ }^{*}$ 02:01 or other common HLA alleles. In summary, the data show that the TCR for $\triangle$ NPM1 upon gene transfer to $\mathrm{CD}^{+}$and $\mathrm{CD} 4^{+} \mathrm{T}$ cells results in specific recognition of CLAVEEVSL as an endogenous neoantigen presented by HLA-A ${ }^{*} 02: 01$ on primary AML with $\triangle \mathrm{NPM} 1$. 
A

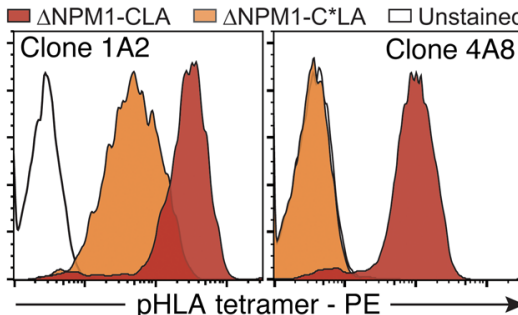

B

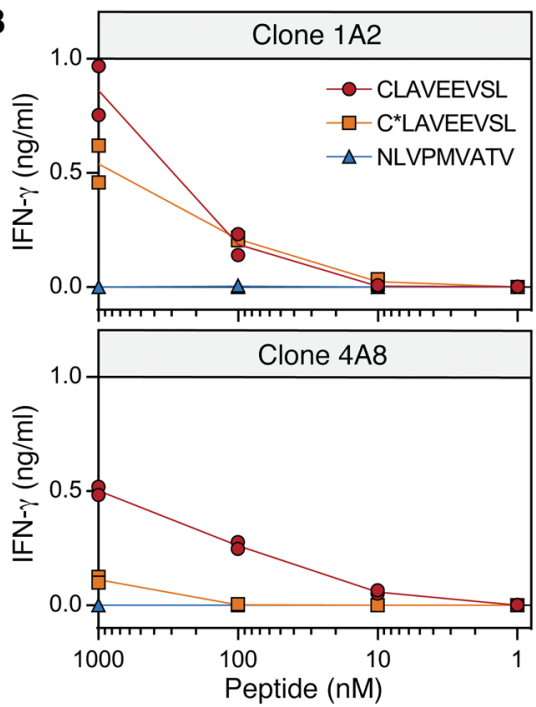

C
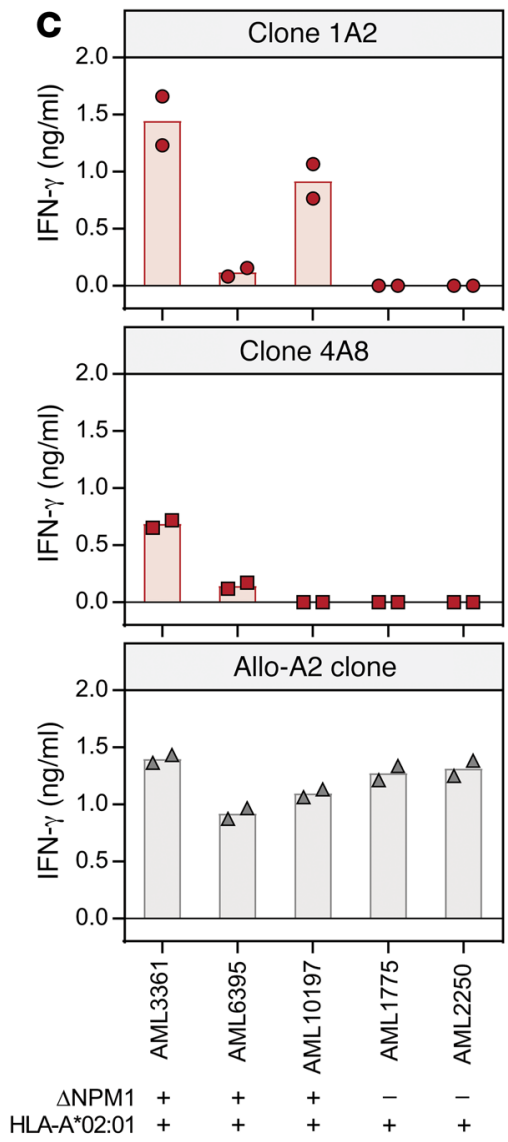

Figure 3. CLAVEEVSL as $\triangle N P M 1$-derived neoantigen. $C D 8^{+} T$ cells specific for $\triangle N P M 1$ were single cell isolated from PBMCs from HLA-A*02:01-positive healthy individuals using a mix of $\triangle N P M 1-C L A$ and $\triangle$ NPM1- $C^{*}$ LA pHLA tetramers. (A) T cell clones were stained with pHLA tetramers. T cell clones $1 A 2$ (left) and $4 A 8$ (right) were both positive for the $\triangle$ NPM1CLA tetramer (red), whereas only clone $1 A 2$ stained with $\triangle N P M 1-C^{*}$ LA (orange). (B) T cell clones $1 A 2$ (upper panel) and 4A8 (lower panel) were tested for reactivity against HLA-A $A^{*} 02: 01$-positive T2 cells exogenously loaded with titrated concentrations of $\triangle$ NPM1 peptide CLAVEEVSL (red circles), the cysteinylated variant $C^{*}$ LAVEEVSL (orange squares), or an irrelevant $\mathrm{HLA}-\mathrm{A}^{*} 02$ :01-binding CMV peptide NLVPMVATV (blue triangles) by IFN- $\gamma$ ELISA. Both T cell clones showed recognition of CLAVEEVSL, and clone $1 \mathrm{~A} 2$ also showed recognition of $\mathrm{C}^{*} \mathrm{LAVEEVSL}$. Release of IFN- $\gamma(\mathrm{ng} / \mathrm{ml})$ in duplicate wells is shown. (C) Clones $1 \mathrm{~A} 2$ (upper panel) and $4 \mathrm{~A} 8$ (middle panel) were tested for reactivity against $5 \mathrm{HLA}-\mathrm{A}^{*} 02: 01-$ positive primary AMLs by IFN- $\gamma$ ELISA. The panel included 3 AMLs with $\triangle N P M 1$ and 2 AMLs with WTNPM1. T cell clone $1 A 2$ reacted against all 3 AMLs with $\triangle N P M 1$, whereas clone $4 A 8$ recognized 2 AMLs. An HLA-A* $02: 01-$ specific alloreactive $T$ cell clone (Allo-A2 clone) was included as a positive control. Release of IFN $-\gamma(\mathrm{ng} / \mathrm{ml})$ in duplicate wells is shown; bars represent mean IFN- $\gamma$ release.
Next, we tested the cytolytic capacity of TCR-transduced $\mathrm{CD}^{+}$and $\mathrm{CD} 4^{+} \mathrm{T}$ cells against primary AML. TCR-transduced T cells were tested against $6 \mathrm{HLA}-\mathrm{A}^{*}$ 02:01-positive AMLs, including 4 samples with $\triangle$ NPM1 and 2 samples with WTNPM1 in a 9-hour ${ }^{51}$ chromium release assay. $\mathrm{CD} 8^{+}$as well as $\mathrm{CD} 4^{+} \mathrm{T}$ cells transduced with the TCR for $\triangle$ NPM1 showed specific lysis of $\triangle$ NPM1 AML, but not WTNPM1 AML (Figure 6), indicating that CLAVEEVSL is a neoantigen that can be efficiently targeted on AML by $\triangle$ NPM1 TCR gene transfer in a CD8 coreceptor-independent fashion.

Finally, in vivo efficacy of TCR-transduced $\mathrm{T}$ cells was investigated in immunodeficient NSG mice engrafted with HLA-A ${ }^{*}$ 02:01-positive OCI-AML3 cells with $\triangle$ NPM1. Two weeks after inoculation of $1 \times 10^{6}$ OCI-AML3 cells transduced with luciferase, mice were either left untreated $(n=4)$ or received a single dose of $4 \times 10^{6} \mathrm{CD} 8 / \mathrm{CD} 4^{+} \mathrm{T}$ cells (ratio 2:3) transduced with the TCR for $\triangle \mathrm{NPM} 1(n=5)$ or with the CMV-specific control TCR $(n=2)$. The data showed a clear antitumor effect in mice treated with the $\triangle$ NPM1-specific TCR by bioluminescent imaging (Figure 7, A and B), resulting in significantly better overall survival than that seen in untreated mice or mice treated with the CMVspecific TCR (Figure 7C). In conclusion, T cells transduced with the TCR for $\triangle \mathrm{NPM} 1$ efficiently kill AML cells in vivo, resulting in prolonged overall survival.

\section{Discussion}

In this study, we demonstrate the relevance of $\triangle \mathrm{NPM} 1$ as a target for immunotherapy of AML. NPM1 is a driver gene that is mutat- ed in 30\%-35\% of patients with AML, and although the exact 4 bp insertion may differ, the same C-terminal 11 aa alternative reading frame is produced by the majority of hotspot mutations. By searching the HLA class I ligandome of 12 primary AMLs, multiple peptides were identified from the alternative reading frame of $\triangle$ NPM1. For one of these peptides, HLA-A ${ }^{*} 02$ :01-binding CLAVEEVSL, we isolated a TCR and demonstrated its in vitro and in vivo potential to target $\triangle$ NPM1 AML upon introduction into $\mathrm{CD} 8^{+}$and $\mathrm{CD} 4^{+} \mathrm{T}$ cells.

Interestingly, patients carrying $\triangle \mathrm{NPM} 1$ without FLT3 mutations or with low allelic ratio $(<0.5)$ FLT3 mutations have a relatively favorable prognosis after chemotherapy $(1,2,6,21,22)$, raising the question of whether an effective in vivo immune response is induced against $\triangle$ NPM1. NPM1 is a nucleocytoplasmic shuttling protein, and as a result of the mutation, $\triangle \mathrm{NPM} 1$ is dislocated from the nucleolus to the cytoplasm, where it is susceptible to proteasomal degradation and processing by the HLA class I antigen presentation pathway (8). Greiner et al. (23) investigated whether in vitro $\mathrm{T}$ cell responses could be induced against 9 HLA-A ${ }^{*} 02: 01-$ binding $\triangle$ NPM1 peptides using PBMCs from healthy individuals and patients with AML. After coculture of $\mathrm{CD} 8^{+} \mathrm{T}$ cells with peptide-loaded PBMCs, $\mathrm{T}$ cell responses against AIQDLCLAV and AIQDLCVAV, but not against CLAVEEVSL, were observed. These 2 peptides were subsequently used to screen 25 AML patients with $\triangle \mathrm{NPM} 1$ for in vivo $\mathrm{T}$ cell responses, and it was shown that overall survival of patients with detectable immune responses was higher than that of patients without immune responses (24). We 
A

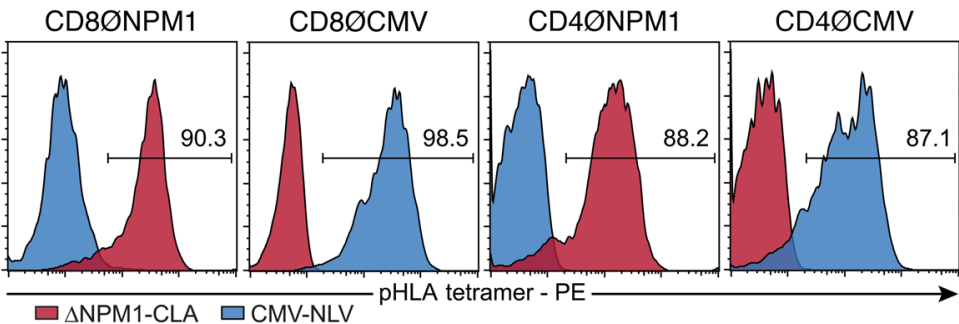

B

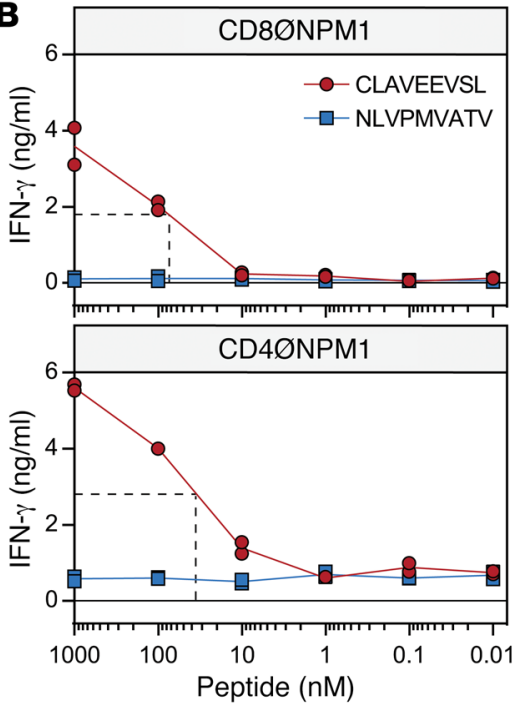

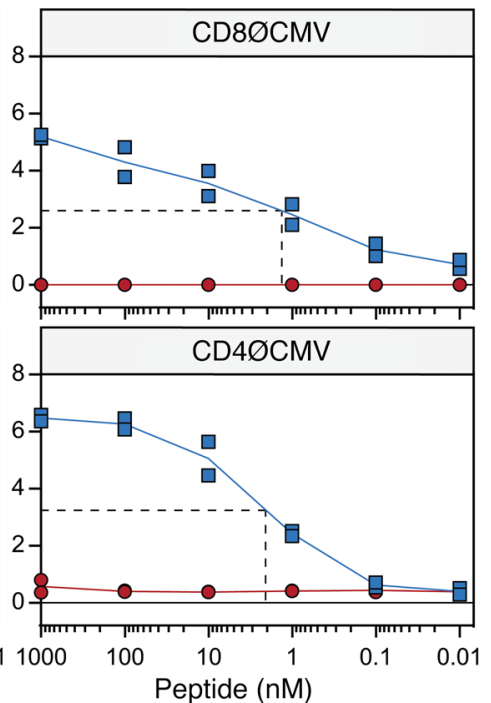

C

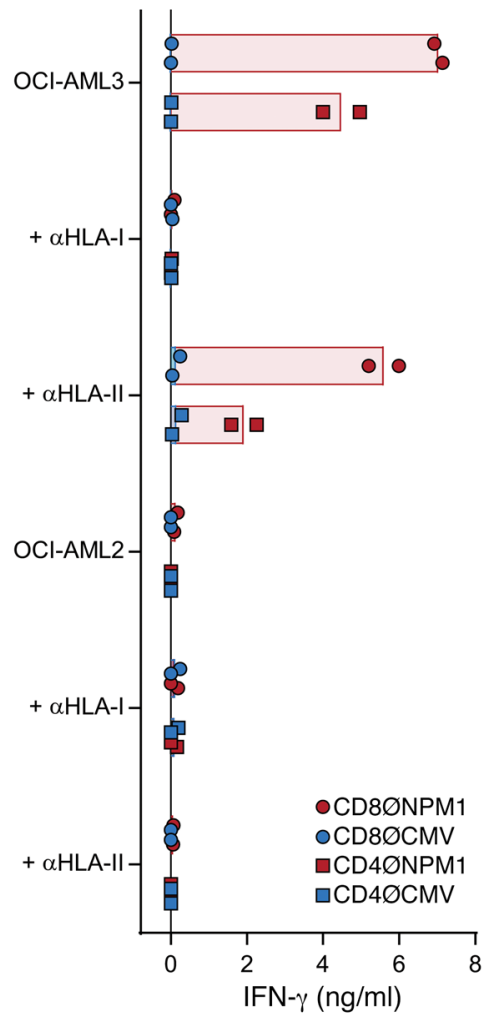

Figure 4. Targeting $\triangle$ NPM1 by TCR gene transfer. $C D 8^{+}$and $C D 4^{+} T$ cells isolated from HLA-A*02:01-positive healthy individuals were transduced with the TCR for $\triangle N P M 1$ from clone $1 A 2$ and a TCR for HLA-A*02:01-binding CMV peptide NLVPMVATV. TCR-transduced T cells were purified by MACS. (A) TCR-transduced T cells were analyzed by flow cytometry using $\triangle N P M 1-C L A$ (red) and CMV-NLV (blue) pHLA tetramers. CD8 $8^{+}$(CD8øNPM1) and CD4 ${ }^{+}$ (CD4ØNPM1) T cells transduced with the TCR for $\triangle N P M 1$ stained with the $\triangle N P M 1-C L A$ tetramer, whereas CD8+ (CD8øCMV) and CD4+ (CD4øCMV) T cells transduced with the CMV-specific TCR showed binding to the CMV-NLV tetramer. Results are shown for donor 1. (B) TCR-transduced T cells were analyzed for reactivity against T2 cells exogenously loaded with titrated concentrations of CLAVEEVSL (red circles) or NLVPMVATV (blue squares) by IFN- $\gamma$ ELISA. CD8ØNPM1 (upper left panel) and CD4ØNPM1 (lower left panel) showed half-maximum recognition of CLAVEEVSL at concentrations of 30-100 nM (dotted lines), but no recognition of NLVPMVATV. Conversely, CD8ØCMV (upper right panel) and CD4ØCMV (lower right panel) reacted against NLVPMVATV, but not CLAVEEVSL. Release of IFN- $\gamma(\mathrm{ng} / \mathrm{ml})$ in duplicate wells is shown for donor 1. (C) TCR-transduced T cells were tested for recognition of HLA-A*02:01positive AML cell lines with $\triangle$ NPM1 (OCI-AML3) or WTNPM1 (OCI-AML2) in the absence or presence of blocking antibodies against HLA class I ( $\alpha$ HLA-I) or HLA class II ( $\alpha \mathrm{HLA}-\mathrm{II})$ by IFN- $\gamma$ ELISA. Recognition of OCI-AML3 by CD8 ${ }^{+}$and CD4+ ${ }^{+}$cells transduced with the TCR for $\triangle N P M 1$ is mediated by HLA class I. Release of IFN- $\gamma(\mathrm{ng} / \mathrm{ml})$ in duplicate wells is shown for donor 2 . Bars represent mean IFN- $\gamma$ release.

analyzed 6 HLA-A ${ }^{*}$ 2:01-positive AML patients with $\triangle$ NPM1 who were in remission after chemotherapy for in vivo immune responses against CLAVEEVSL, but were unable to detect tetramerpositive $\mathrm{T}$ cells, indicating that in vivo immune responses against CLAVEEVSL in these 6 patients were below the threshold of detection and emphasizing the need to develop immunotherapy to target this $\triangle$ NPM1 neoantigen on AML.

Although only cysteinylated C*LAVEEVSL was identified in the HLA class I ligandome of primary AML by MS/MS, clone 1A2 recognized both $C^{*}$ LAVEEVSL and CLAVEEVSL when pulsed as synthetic peptides on T2 cells and could be stained with $\triangle$ NPM1CLA as well as $\triangle$ NPM1-C ${ }^{\star}$ LA tetramers. In contrast, clone 4A8 recognized CLAVEEVSL, but not $C^{*}$ LAVEEVSL, and only the $\triangle$ NPM1-CLA tetramer could bind to the clone. Despite its failure to recognize cysteinylated $C^{*}$ LAVEEVSL, clone 4 A8 reacted against 2 of the 3 AMLs tested. Although this suggests that uncysteinylated $\triangle$ NPM1 peptides can also be presented on AML, our elution data demonstrate that cysteinylated $\triangle$ NPM1 peptides are more abun- dant, since $C^{*}$ LAVEEVSL and C*LAVEEVSLRK were identified as HLA class I ligands on 4 different AMLs, while uncysteinylated variants were not detected. Based on its capacity to recognize $C^{*}$ LAVEEVSL, the TCR from clone $1 \mathrm{~A} 2$ was isolated and investigated for its potential to target $\triangle$ NPM1 AML after TCR gene transfer.

Current immunotherapies often exploit cancer-associated antigens to stimulate antitumor immunity $(9,10)$. Whereas most vaccination trials have shown limited clinical efficacy, possibly due to central $\mathrm{T}$ cell tolerance as a result of low antigen expression on healthy tissues, clinical efficacy of CAR and TCR gene therapy can be strong. However, due to low antigen expression on healthy tissues, antitumor immunity is often accompanied by severe side effects $(9,10,12)$. For instance, CAR therapy targeting CD123 on AML shows promising antitumor responses in preclinical models (25), but also severe myeloablation, probably due to low CD123 expression on healthy hematopoietic stem cells (26). PRAME and WT1 are promising antigens for targeting AML by TCR gene therapy, but low antigen expression on healthy tissues remains a risk 


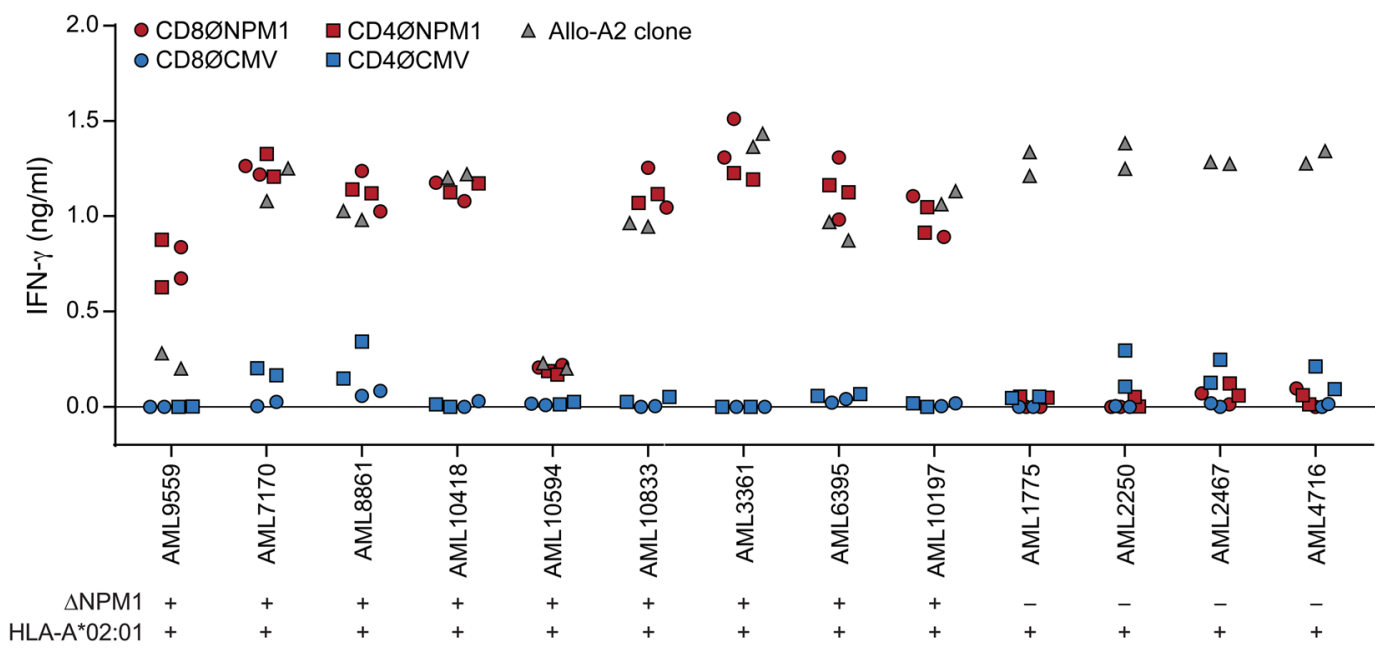

Figure 5. Recognition of primary AMLs after $\triangle N P M 1$ TCR gene transfer. TCR-transduced CD8 ${ }^{+}$and $C D 4^{+}$T cells were tested for reactivity against a panel of 13 HLA-A*02:01-positive primary AMLs, including 9 samples with $\triangle N P M 1$ and 4 samples with WTNPM1 by IFN- $\gamma$ ELISA (Supplemental Table 4). CD8 ${ }^{+}$ (CD8ØNPM1; red circles) and CD4+ (CD4ØNPM1; red squares) T cells transduced with the TCR for $\triangle N P M 1$ reacted against all 9 AMLs with $\triangle N P M 1$, whereas none of the AMLs were specifically recognized by CD8+ (CD8ØCMV; blue circles) or CD4+ (CD4øCMV; blue squares) T cells after transfer of the CMV-specific TCR. The allo-A2 clone (gray triangles) was included as a positive control. Release of IFN- $\gamma(\mathrm{ng} / \mathrm{ml})$ in duplicate wells is shown for donor 1.

for toxicity (27-29). In contrast with cancer-associated antigens, which are encoded by unmutated genes, neoantigens are created by tumor-specific mutations that are absent in healthy tissues, and high-affinity $\mathrm{T}$ cells are therefore not deleted by thymic selection (13-15). This may explain why neoepitope vaccination induces broad and diverse immune responses in stage III/IV melanoma patients (30-32). Likewise, due to absence in healthy tissues, TCR gene transfer for neoantigens is expected to mediate antitumor immunity with no or limited side effects $(13,15)$.

Since CLAVEEVSL is a neoantigen, on-target toxicity is not expected for the $\triangle$ NPM1-specific TCR. This is supported by lack of detection of $\triangle$ NPM1 in clonal hematopoiesis, which is characterized by clonal expansion of blood cells with one or more somatic mutations $(33,34)$, and the fact that the $\triangle$ NPM1-specific TCR has been isolated from an HLA-A $\mathrm{A}^{*}$ 2:01-positive healthy individual, who apparently did not have a deletion of this TCR in the thymus. Although on-target toxicity was not anticipated, we measured reactivity of the $\triangle$ NPM1-specific TCR against HLA-A ${ }^{*} 02: 01-$ positive mature dendritic cells and EBV-LCL, which also express a variety of other HLA alleles. The TCR for $\triangle$ NPM1 lacked reactivity against these healthy cells, with strong antigen processing and presentation capacity, thereby excluding on-target reactivity against a peptide resembling CLAVEEVSL produced by alternative translation of the WTNPM1 gene and off-target reactivity against a ubiquitous peptide presented by HLA- ${ }^{*} 02: 01$ or another common HLA allele. However, potential off-target reactivity against a tissue-restricted peptide or a ubiquitous peptide presented by a rare HLA allele cannot be excluded and should be further evaluated before start of a clinical $\triangle$ NPM1 TCR gene study.

Clinical efficacy of TCR gene therapy is dependent on specificity and expression of the target antigen, but also relies on affinity of the transferred TCR (35). Our data showed that the TCR for $\triangle \mathrm{NPM} 1$ is able to recognize and lyse primary AML in a CD8 coreceptor-independent manner. Although $\mathrm{CD} 4^{+} \mathrm{T}$ cells are tradition- ally known to provide help to $\mathrm{CD} 8^{+} \mathrm{T}$ cells, there is now substantial evidence that $\mathrm{CD} 4^{+} \mathrm{T}$ cells can also mediate tumor rejection in the absence of $\mathrm{CD} 8^{+} \mathrm{T}$ cells and that they may even be essential for effective antitumor immunity (36-39). Coadministration of $\mathrm{CD} 8^{+}$ and $\mathrm{CD} 4^{+} \mathrm{T}$ cells expressing the same antigen receptor may thus be preferable and might result in superior antitumor immunity. This is supported by mouse studies $(40,41)$ and by Turtle et al. $(42,43)$, who demonstrated in humans that adoptive transfer of $\mathrm{CD}^{+}$and $\mathrm{CD} 4^{+} \mathrm{T}$ cells expressing the same $\mathrm{CD} 19$-specific CAR resulted in complete remission in a substantial number of patients with relapsed or refractory B cell malignancies.

An advantage of gene therapy is that the CAR or TCR can be introduced into distinct $\mathrm{T}$ cell subsets with superior in vivo persistence and antitumor efficacy, such as stem cell memory and central memory T cells. Notably, the culture period to produce tumor-specific $\mathrm{T}$ cells is relatively short and permits conditions for maintaining a less differentiated $\mathrm{T}$ cell phenotype and infusion of a well-defined $\mathrm{T}$ cell product $(44,45)$. On the other hand, gene therapy could lead to immune escape of the tumor by loss of antigen expression (46). In particular, HLA class I downregulation through loss of heterozygosity of HLA alleles or B2M mutations is an escape mechanism that may hamper efficacy of TCR gene therapy (32, 47-49). Other escape mechanisms mainly affect genes involved in the IFN- $\gamma$ signaling pathway, such as apelin receptor (APLNR) and Janus kinases (JAK1 and JAK2), which are also crucial in antitumor responses by CAR gene therapy and other immunotherapeutic approaches (49-51). Finally, another specific drawback of TCR gene therapy is the risk of TCR chain mispairing between introduced and endogenous TCR $\alpha$ and $\beta$ chains, resulting in reduced efficacy and potential toxicity by new TCRs with unknown specificities $(52,53)$. Although preferential pairing of the introduced TCR can be stimulated by a disulfide bridge between $\alpha$ and $\beta$ chains (54), mispairing cannot entirely be prevented. It is noteworthy that strategies including gene editing by TALEN, 

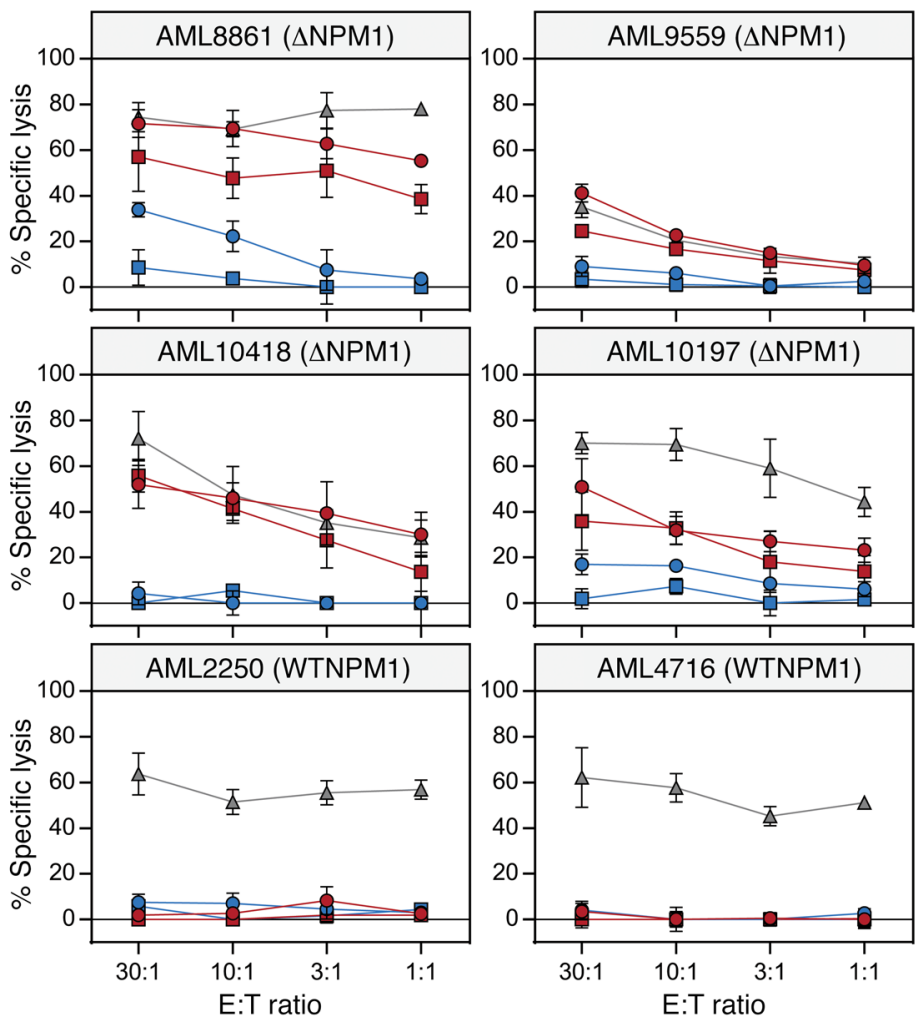

Figure 6. Lysis of primary AMLs after $\triangle$ NPM1 TCR gene transfer. TCR-transduced $\mathrm{CD} 8^{+}$and $\mathrm{CD}^{+} \mathrm{T}$ cells were tested for cytolytic capacity by a 9-hour ${ }^{51} \mathrm{Cr}$-release assay on $6 \mathrm{HLA}-\mathrm{A}^{*} 02: 01-$ positive primary $A M L s$, including 4 samples with $\triangle N P M 1$ and 2 samples with WTNPM1. CD8 (CD8ØNPM1; red circles) and CD4+ (CD4ØNPM1; red squares) T cells transduced with the TCR for $\triangle N P M 1$ showed specific lysis of all 4 AMLs with $\triangle N P M 1$, whereas none of the AMLs were specifically lysed by CD8+ (CD8ØCMV; blue circles) or CD4+ (CD4øCMV; blue squares) T cells after transfer of the CMV-specific TCR. The allo-A2 clone (gray triangles) was included as a positive control. Data represent mean percentage of specific lysis in triplicate wells \pm SD for donor 2 . zinc-finger nucleases, and CRISPR/Cas9 completely abrogate expression of endogenous TCRs and can provide a solution for unwanted TCR chain mispairing $(28,55-57)$.

In conclusion, since patients with relapsed or refractory AML after intensive chemotherapy or alloSCT have an extremely poor prognosis $(1,2), \triangle \mathrm{NPM} 1 \mathrm{TCR}$ gene therapy may significantly contribute to survival and potential cure of these patients for whom there are often no other treatment options. Recently, $\triangle$ NPM1 has also been shown as a reliable marker for measuring minimal residual disease (58). Persistence of $\triangle$ NPM1 transcripts as detected by quantitative reverse transcriptase PCR in AML patients after chemotherapy strongly predicted disease relapse within 3 years of follow-up. These findings support that $\triangle \mathrm{NPM} 1$ is a clonal driver mutation that is retained in AML cells to maintain their malignant phenotype and suggest that $\triangle \mathrm{NPM} 1$ as a marker for disease status can be used for optimal timing and treatment of patients with relapsed or refractory AML by preemptive $\triangle$ NPM1 TCR gene therapy. If proven successful, it may even replace alloSCT as effective therapy for AML across all risk categories. Altogether, this emphasizes the relevance of $\triangle \mathrm{NPM} 1$ as a target for T cell immunotherapy and clinical potential of this $\triangle$ NPM1-specific TCR.

\section{Methods}

Sample collection and cell culture. Peripheral blood and bone marrow samples were collected from patients with AML and healthy individuals. Peripheral blood and bone marrow mononuclear cells were isolated by Ficoll-Isopaque separation and cryopreserved. For isolation of PBMCs from HLA-A*02:01-typed healthy individuals, buffy coats were ordered from Sanquin. $\mathrm{T}$ cells were cultured in $\mathrm{T}$ cell medium (TCM) consisting of Iscove's Modified Dulbecco's Medium (IMDM) (Lonza) supplemented with 5\% heat-inactivated FBS (Gibco, Ther- mo Fisher Scientific), 5\% human serum, 1.5\% $200 \mathrm{mM}$ L-glutamine (Lonza), 1\% 10,000 U/ml penicillin/streptomycin (Lonza), and 100 $\mathrm{IU} / \mathrm{ml}$ IL-2 (Novartis). AML cell lines expressing WTNPM1 (OCIAML2) and $\triangle$ NPM1 (OCI-AML3) were ordered from DSMZ. AML cell lines and primary AML, EBV-LCL, and T2 cells (ATCC) were cultured in IMDM containing 10\% FBS, 1.5\% L-glutamine, and 1\% penicillin/streptomycin. Monocytes were isolated from PBMCs by magnetic-activated cell sorting (MACS) (Miltenyi Biotec) with CliniMACS CD14 beads (Miltenyi Biotec), and mature DCs were cultured as described previously (59). All cell lines were mycoplasma negative, as determined by regular testing using the PlasmoTest Mycoplasma Detection Kit (InvivoGen).

HLA class I ligandome of primary AML. Peptide elution was performed as outlined previously (60). In brief, cell pellets of 12 primary AMLs were lysed in $50 \mathrm{mM}$ Tris- $\mathrm{HCl}, 150 \mathrm{mM} \mathrm{NaCl}, 5 \mathrm{mM}$ ethylenediaminetetraacetate, and $0.5 \%$ Zwittergent 3-12 ( $\mathrm{pH}$ 8.0) supplemented with cOmplete Protease Inhibitor (Sigma-Aldrich). After 2 hours of tumbling in lysis buffer at $4^{\circ} \mathrm{C}$, cell lysates were centrifuged for 10 minutes at $1000 \mathrm{~g}$ at $4^{\circ} \mathrm{C}$. The supernatant was subsequently centrifuged for 35 minutes at $13,000 \mathrm{~g}$ at $4^{\circ} \mathrm{C}$, precleared with Protein A Sepharose CL-4B beads (GE Healthcare Life Sciences), and subjected to an immunoaffinity column with dimethyl pimelidateimmobilized W6/32 antibody ( $3 \mathrm{mg} / \mathrm{ml}$ resin) on Protein A Sepharose CL-4B beads with a flow rate of $1 \mathrm{ml} / \mathrm{min}$. After washing with 5 to 10 column volumes of lysis buffers and $10 \mathrm{mM}$ Tris- $\mathrm{HCl}(\mathrm{pH} 8.0)$ buffers with $1 \mathrm{M}, 120 \mathrm{mM}$, and no $\mathrm{NaCl}$, bound HLA class I-peptide complexes were eluted from the column and dissociated with 3 to 4 column volumes of $10 \%$ acetic acid. Peptides were separated from HLA class I molecules via passage through a $10 \mathrm{kDa}$ membrane (Macrosep Advance Centrifugal Devices With Supor Membrane, Pall Corp.). The filtrate was freeze dried. 

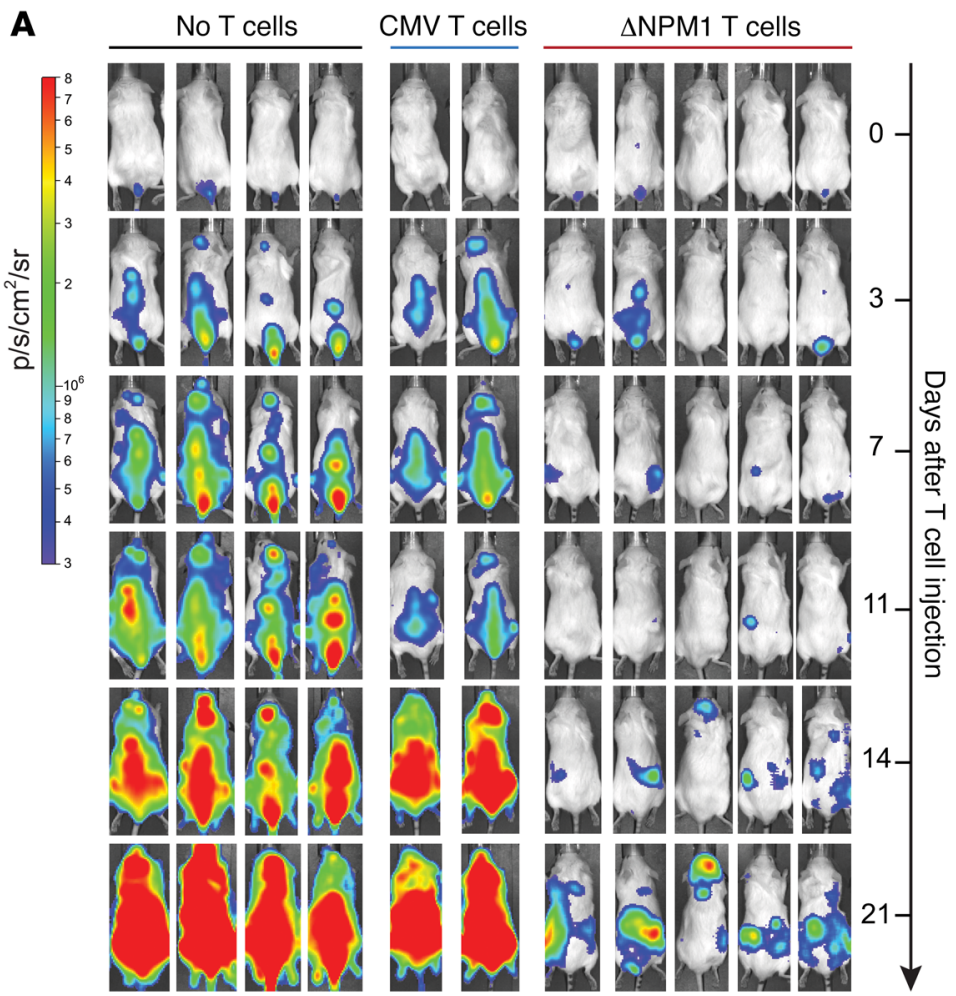
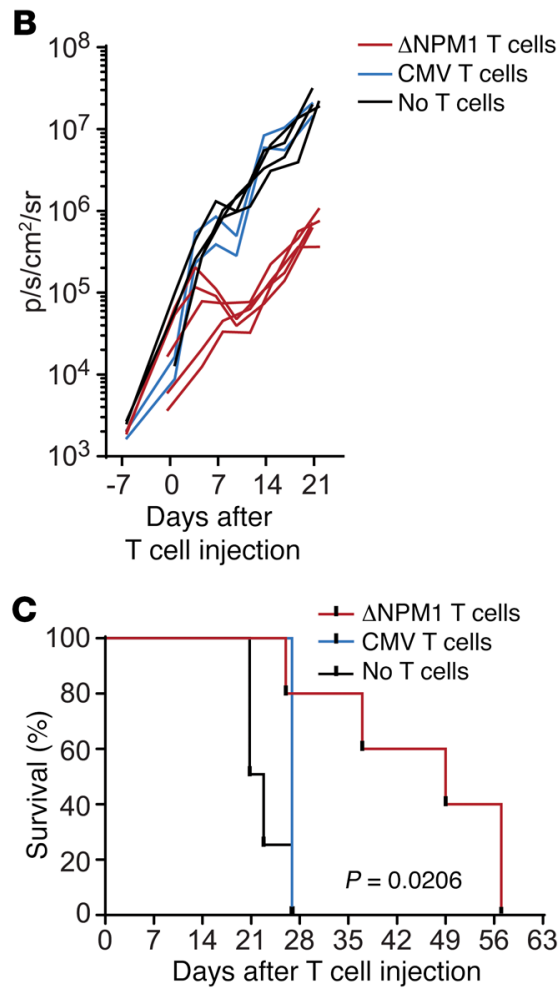

Figure 7. In vivo antitumor efficacy after $\triangle$ NPM1 TCR gene transfer. Male NSG mice were engrafted with $1 \times 10^{6} \mathrm{HLA}-\mathrm{A}^{*} 02: 01-$ positive $0 \mathrm{Cl}-\mathrm{AML} 3$ cells with $\triangle$ NPM1. OCI-AML3 cells were transduced with luciferase to follow in vivo tumor growth by bioluminescence imaging. Two weeks after tumor inoculation, mice were either left untreated or injected i.v. with $4 \times 10^{6} \mathrm{CD}^{+} / \mathrm{CD} 4^{+} \mathrm{T}$ cells (2:3 ratio) transduced with the TCR for $\triangle N P M 1$ or with the CMV-specific control TCR. TCR-transduced T cells were produced from HLA-A*02:01-positive healthy donor 3. (A and B) After T cell injection, tumor burden was followed twice per week for 21 days. In mice receiving $C D 8^{+} / C D 4^{+} T$ cells transduced with the TCR for $\triangle N P M 1$ (NNPM1 T cells; $n=5$; red), tumor load was significantly reduced within 2 weeks of T cell transfer, resulting in delayed tumor outgrowth as compared with that in untreated mice (no T cells; $n=4$; black) and mice treated with $\mathrm{CD}^{+} / \mathrm{CD} 4^{+}$T cells transduced with the CMV-specific control TCR (CMV T cells; $n=2$; blue). (C) Kaplan-Meier curve showing better overall survival of mice treated with the $\triangle$ NPM1-specific TCR ( $n=5$; red line) as compared with untreated mice ( $n=4$; black line) or mice treated with the CMVspecific control TCR ( $n=2$; blue line). $P=0.0206$, log-rank (Mantel-Cox) test.

Eluted peptide pools were fractionated by strong cation exchange chromatography (SCX) with a homemade $15 \mathrm{~cm}$ SCX column (320 $\mu \mathrm{m}$ inner diameter; polysulfoethyl A, $3 \mu \mathrm{m}$, Poly LC) run at $4 \mu \mathrm{l} / \mathrm{min}$. Gradients were run for 10 minutes at 100\% solvent A (100/0.1 water/ trifluoroacetic acid $\mathrm{v} / \mathrm{v})$, after which a linear gradient started to reach $100 \%$ solvent B $(65 / 35 / 0.1250 \mathrm{mM} \mathrm{KCl} /$ acetonitrile/trifluoroacetic acid v/v/v) over 15 minutes, followed by $100 \%$ solvent C (65/35/0.1500 $\mathrm{mM} \mathrm{KCl} /$ acetonitrile/trifluoroacetic acid v/v/v) over the next 15 minutes. The gradient remained at $100 \%$ solvent $C$ for 5 minutes and then switched again to $100 \%$ solvent A. Twenty $4 \mu \mathrm{l}$ fractions were collected in vials prefilled with $20 \mu \mathrm{l} 95 / 3 / 0.1$ water/acetonitrile/formic acid $\mathrm{v} / \mathrm{v} / \mathrm{v}$. Peptide fractions were lyophilized, dissolved in 95/3/0.1 water/ acetonitril/formic acid v/v/v and subsequently analyzed by data-dependent MS/MS on either an LTQFT Ultra equipped with a nanoflow liquid chromatography 1100 HPLC system (Agilent Technologies), as previously described (61), or a Q Exactive mass spectrometer equipped with an easy-nLC 1000 (Thermo Fisher Scientific). Peptides were trapped at $6-10 \mu \mathrm{l} / \mathrm{min}$ on a $1.5 \mathrm{~cm}$ column $(100 \mu \mathrm{m}$ internal diameter; ReproSil-Pur C18-AQ, $3 \mu \mathrm{m}$, Dr. Maisch HPLC GmbH) and eluted to a $20 \mathrm{~cm}$ column (50 $\mu \mathrm{m}$ internal diameter; ReproSil-Pur C18-AQ, $3 \mu \mathrm{m})$ at 150 $\mathrm{nl} / \mathrm{min}$. The column was developed with a 120-minute gradient from $0 \%$ to $40 \%$ acetonitrile in $0.1 \%$ formic acid. The end of the column was drawn to a tip (internal diameter about $5 \mu \mathrm{m}$ ) from which the eluent was sprayed into the mass spectrometer. Full-scan MS spectra were acquired in the FT-ICR with a resolution of 25,000 at a target value of 3,000,000. The 2 most intense ions were isolated for accurate mass measurements by a selected ion monitoring scan in FT-ICR with a resolution of 50,000 at a target accumulation value of 50,000. The selected ions were then fragmented in the linear ion trap using collision-induced dissociation at a target value of 10,000. The QExactive mass spectrometer was operated in top10 mode. Parameters were resolution 70,000 at an AGC target value of 3,000,000/maximum fill time of $20 \mathrm{~ms}$ (full scan) and resolution 17,500 at an AGC target value of 100,000/maximum fill time of 60 $\mathrm{ms}$ for MS/MS at an intensity threshold of 17,000. Apex trigger was set to 1 to 10 seconds, and allowed charges were 2-6. The Orbitrap Fusion LUMOS mass spectrometer was operated in data-dependent MS/MS (top-N mode), with collision energy at $32 \mathrm{~V}$ and recording of the MS2 spectrum in the orbitrap. In the master scan (MS1), the resolution was 60,000 and the scan range $300-1400$ at an AGC target of 400,000 at maximum fill time of $50 \mathrm{~ms}$. The dynamic exclusion was set after $n=1$ with an exclusion duration of 20 seconds. Charge states $1-4$ were included. For MS2, precursors were isolated with the quadrupole with an isolation width of 1.2 Da. HCD collision energy was set to $32 \mathrm{~V}$. First mass was set to $110 \mathrm{Da}$. The MS2 scan resolution was 30,000, with an AGC target of 50,000 at maximum fill time of $100 \mathrm{~ms}$. Proteome Discoverer version 2.1 (Thermo Fisher Scientific) was used for peptide 
and protein identification, using the mascot node for identification, using mascot version 2.2.04 with the UniProt Homo Sapiens database (UP000005640; Jan 2015; 67,911 entries). Methionine oxidation and cysteinylation of cysteine were set as a variable modification. Peptide assignments were made with a precursor tolerance of $10 \mathrm{ppm}$ and MS/ MS fragment tolerance of $20 \mathrm{mmu}$ for the Q Exactive data and $2 \mathrm{ppm}$ and 0.5 Da for LTQFT Ultra data. Identification of the $\triangle$ NPM1-derived peptide was confirmed by its synthetic counterpart.

Peptide synthesis and pHLA tetramer production. Peptides were synthesized by standard Fmoc chemistry and dissolved in DMSO. Cysteinylation of peptides was performed by treating $1 \mathrm{mM}$ peptide with 2 $\mathrm{mM}$ 1,4-dithiothreitol in $50 \mathrm{mM}$ ammonium bicarbonate for $15 \mathrm{~min}$ utes at $50^{\circ} \mathrm{C}$, followed by addition of $10 \mathrm{mM}$ free cysteine and $15 \mathrm{mM}$ $\mathrm{H}_{2} \mathrm{O}_{2}$ for 30 minutes at room temperature (RT). pHLA tetramers were produced as outlined previously, with minor modifications $(62,63)$. In brief, monomers consisting of recombinant $\mathrm{HLA}^{*} \mathrm{~A}^{*} 02$ :01 heavy chain and human B2M were purified by gel-filtration HPLC and biotinylated. After folding with the appropriate peptide, pHLA tetramers were generated by adding PE- or APC-conjugated streptavidin (Invitrogen, Thermo Fisher Scientific). UV-exchange pHLA tetramers were produced by exposing biotinylated HLA-A ${ }^{*} 2: 01$ monomers containing UV-sensitive peptide to $366 \mathrm{~nm}$ UV light in the presence of cysteinylated $\triangle$ NPM1 peptide. After 1 hour of peptide exchange, monomers were incubated for 1 hour at $4^{\circ} \mathrm{C}$ followed by centrifugation at 4000 $g$ for 10 minutes at $15^{\circ} \mathrm{C}$. pHLA tetramers were produced by adding streptavidin-conjugated PE to supernatants and were stored at $4^{\circ} \mathrm{C}$.

Antibodies and FACS analysis. T cells were stained with FITC-conjugated antibodies against CD3 (catalog 555339), CD4 (catalog 555346), CD8 (catalog 555366) (BD Biosciences), and TCR-Vק5.1 (catalog IM1552, Beckman Coulter); APC-conjugated antibodies against CD3 (catalog 555342), CD4 (catalog 555349), CD8 (catalog 555369), and mouse TCR-C $\beta$ (catalog 553174); and PE-conjugated pHLA tetramers and antibodies against CD3 (catalog 555340), CD4 (catalog 555347), and CD8 (catalog 555367) (BD Biosciences). Cells were measured on a BD FACSCalibur II (BD Biosciences) using BD CellQuest Pro software (BD Biosciences), and analysis was performed with FlowJo software.

$T$ cell isolation and culture. pHLA tetramer-positive $\mathrm{CD}^{+} \mathrm{T}$ cells were isolated from PBMCs from AML patients and healthy individuals as previously described (64). In short, PBMCs from $\mathrm{HLA}^{-}{ }^{*}$ 02:01-positive AML patients and healthy individuals were stained with $\mathrm{PE}$-conjugated pHLA tetramers containing $\triangle$ NPM1 peptides for 1 hour at $4^{\circ} \mathrm{C}$ followed by MACS isolation using anti-PE MicroBeads (Miltenyi Biotec). Isolated cells were stained with Alexa Fluor-conjugated antiCD8 (catalog MHCD0829) (Invitrogen), FITC-conjugated anti-CD4, anti-CD14 (catalog 555397), and anti-CD19 (catalog 555412) (BD Biosciences), and tetramer-positive $\mathrm{CD}^{+} \mathrm{T}$ cells were single cell sorted by a BD FACSAria III cell sorter (BD Biosciences) using BD FACSDiva version 6 software. Single T cells were stimulated with 50,000 irradiated allogeneic PBMCs, 5,000 irradiated allogeneic EBV-LCL, and 0.8 $\mu \mathrm{g} / \mathrm{ml}$ PHA (Oxoid Microbiology Products, Thermo Fisher Scientific) in $100 \mu \mathrm{lCM}$ per well in 96-well U-bottom culture plates (Costar, Sigma-Aldrich). Growing T cell clones were restimulated every 10-14 days with irradiated feeder cells and PHA.

$T$ cell reactivity assays. T cell recognition was measured by IFN- $\gamma$ ELISA (Sanquin). Stimulator cells (30,000 or 10,000 cells for EBVLCL) were coincubated with T cells (2000 cells) in $40 \mu \mathrm{l}$ TCM per well in 384-well flat-bottom plates (Greiner Bio-One). After overnight coincubation, culture supernatants were harvested to measure IFN- $\gamma$ release. In peptide recognition assays, T2 cells (15,000 cells) were preincubated for 30 minutes at $37^{\circ} \mathrm{C}$ with titrated peptide concentrations and washed twice before coincubation with $\mathrm{T}$ cells. In blocking assays, target cells $(10,000$ cells) were preincubated for 60 minutes at RT with antibodies blocking HLA class I (W6/32) or HLA class II (PdV5.2) before addition of T cells. T cell-mediated cytotoxicity was measured in ${ }^{51}$ chromium release assays. AML cells were labeled with $100 \mu \mathrm{Ci} \mathrm{Na}{ }_{2}^{51} \mathrm{CrO}_{4}$ for 1 hour at $37^{\circ} \mathrm{C}$, washed, and coincubated with $\mathrm{T}$ cells at various effector-to-target (E:T) ratios in $100 \mu \mathrm{lCM}$ per well in 96-well U-bottom culture plates (Costar). Spontaneous and maximum ${ }^{51} \mathrm{Cr}$ release were measured in separate plates containing $100 \mu \mathrm{l} \mathrm{TCM}$ or $100 \mu \mathrm{l}$ TCM with $1 \%$ Triton-X 100 per well (Sigma-Aldrich), respectively. After 9 hours of coincubation, $25 \mu$ l supernatants were harvested and transferred to 96-well LumaPlates (PerkinElmer). ${ }^{51} \mathrm{Cr}$ release in cpm was measured on a 2450 Microbeta $^{2}$ plate counter (PerkinElmer).

TCR cloning and production of retroviral supernatants. TCR $\alpha$ and $\beta$ chain usage of clone 1A2 was determined as previously described with minor modifications (65). In brief, $\mathrm{T}$ cells were lysed and mRNA was isolated by the Dynabeads mRNA DIRECT Kit (Invitrogen). TCRspecific cDNA was generated using 2 TCR-C $\beta$ primers, a TCR-C $\alpha$ primer, an SA.rt anchor template-switching oligonucleotide (TSO), and SMARTScribe Reverse Transcriptase (Takara, Clontech) (66). During first-strand cDNA synthesis, SMARTScribe reverse transcriptase adds a 3 ' nontemplated polycytosine terminus, which allows for annealing of the TSO and second-strand cDNA synthesis (66). TCR amplification was performed by PCR using Phusion Flash (Thermo Fisher Scientific), an anchor-specific primer, and nested primers annealing to TCR-C $\alpha$ or $-\mathrm{C} \beta$ regions. TCR sequences for clone $1 \mathrm{~A} 2$ were identified as TRAV12-2 and TRBV5-1 by Sanger sequencing (Macrogen) and the ImMunoGeneTics (IMGT) database (67). Codon-optimized TRAV122 and TRBV5-1 sequences were synthesized and cloned in MP71TCR-flex retroviral vector by GenScript. In MP71-TCR-flex, murine TCR-C $\alpha$ and $-C \beta$ regions with additional cysteine residues to promote preferential pairing of the TCR are linked by a P2A sequence (20). The construct was transfected into packaging cells $\phi$-NX-A (ATCC), and retroviral supernatants 48 and 72 hours after transfection were harvested and frozen at $-80^{\circ} \mathrm{C}$. The MP71-TCR-flex vector and MP71TCR-flex encoding a TCR for HLA-A ${ }^{*}$ 2:01-binding CMV peptide NLVPMVATV was provided by T.N. Schumacher (Division of Immunology, Netherlands Cancer Institute, Amsterdam, Netherlands).

TCR gene transfer. PBMC from 3 HLA- ${ }^{*} 02$ :01-positive healthy individuals (donor 1, 2 and 3 ) were thawed, and $\mathrm{CD} 4^{+}$and $\mathrm{CD} 8^{+} \mathrm{T}$ cells were isolated by MACS using anti-CD4 MicroBeads (Miltenyi Biotec) followed by the $\mathrm{CD} 8^{+} \mathrm{T}$ cell Isolation Kit (Miltenyi Biotec). $\mathrm{CD} 8^{+}$and $\mathrm{CD}^{+} \mathrm{T}$ cells were stimulated with irradiated autologous feeders and $0.8 \mu \mathrm{g} / \mathrm{ml}$ PHA in 24-well flat-bottom culture plates (Costar). Two days after stimulation, $\mathrm{T}$ cells were transferred to 24 -well flat-bottom suspension culture plates (Greiner Bio-One) for retroviral transduction. Prior to the addition of T cells, the plates were coated with $30 \mu \mathrm{g} /$ $\mathrm{ml}$ retronectin (Takara, Clontech) and blocked with 2\% human serum albumin (Sanquin). Retroviral supernatants were added, and plates were centrifuged at $3000 \mathrm{~g}$ for 20 minutes at $4^{\circ} \mathrm{C}$. T cells were added to the plates with viral supernatants at 300,000 cells per well. After overnight incubation, $\mathrm{T}$ cells were transferred to 24 -well flat-bottom culture plates. At day 6 after transduction, TCR-transduced T cells were stained with APC-conjugated anti-mouse TCR-C $\beta$ for 15 min- 
utes at $4^{\circ} \mathrm{C}$, followed by MACS isolation using anti-APC MicroBeads (Miltenyi Biotec). TCR-transduced T cells were restimulated on days 10-14 with irradiated allogeneic PBMCs, EBV-LCL, and $0.8 \mu \mathrm{g} / \mathrm{ml}$ PHA and enriched by MACS using APC-conjugated anti-mouse TCR$\mathrm{C} \beta$ and anti-APC MicroBeads prior to analysis.

In vivo antitumor efficacy. Male NOD.Cg-Prkdc(scid) Il2rg(tm1Wjl)/ SzJ (NOD scid gamma, NSG) mice (The Jackson Laboratory) were maintained in individually ventilated cages in groups, and food and water were provided ad libitum. Mice of 8 to 12 weeks were injected i.v. with $1 \times 10^{6}$ OCI-AML3 cells that were transduced with luciferase $(\mathrm{pCDH}-$ EF1-Luc2-P2A-tdTomato Red; a gift from Kazuhiro Oka, Department of Molecular \& Cellular Biology, Baylor College of Medicine, Houston, Texas, USA) (Addgene plasmid, catalog 72486) and sorted to greater than $98 \%$ purity by flow cytometry. For tumor visualization, mice were injected i.p. with $200 \mu \mathrm{l} 7.5 \mathrm{mM}$ D-luciferine (Cayman Chemical Co.) and anesthetized with $3 \%-4 \%$ isoflurane. Bioluminescent images were obtained using a CCD camera (IVIS spectrum, PerkinElmer). Two weeks after tumor cell inoculation, mice were injected i.v. with $4 \times 10^{6}$ TCR-transduced $\mathrm{CD}^{+} / \mathrm{CD} 4^{+} \mathrm{T}$ cells (2:3 ratio) or left untreated.

Data and materials availability. pHLA tetramers for CLAVEEVSL, $C^{*}$ LAVEEVSL, and NLVPMVATV, retroviral vectors and supernatants for mutant and WT NPM1, the allo-HLA-A ${ }^{*}$ 2:01 clone, and primary AML must be obtained through a material transfer agreement (MTA).

For further information, see Supplemental Methods.

Statistics. Statistical significance of survival data was assessed using the log-rank (Mantel-Cox) test. Statistical analyses were performed using Prism software (GraphPad Software, version 6). $P<0.05$ was considered significant.

Study approval. For this study, materials were used from the Leiden University Medical Center Biobank for Hematological Diseases. This study was approved by the Institutional Review Board of the Leiden University Medical Center (IRB LUMC approval number B16.039). Materials from patients and healthy individuals were collected after written informed consent according to the Declaration of Helsinki. All animal studies were conducted in accordance with institutional guidelines after obtaining permission from the national Ethical Committee for Animal Research (AVD116002017891) and in accordance with Dutch laws on animal experiments.

\section{Author contributions}

DIVDL designed, performed, analyzed, and interpreted all in vitro experiments and wrote the manuscript. RMR designed, performed, analyzed, and interpreted in vivo experiments and wrote the manuscript. MWH performed experiments and constructed retroviral expression vectors. RSH determined TRAV and TRBV usage and constructed retroviral expression vectors. RCMDJ performed in vivo experiments and produced pHLA tetramers. MGDK generated and analyzed peptide elution data and produced pHLA tetramers. DMVDS generated peptide elution data and contributed to the TCR gene transfer protocol. AHDR performed and analyzed MS experiments. CK performed in vivo experiments. HMB contributed to the T cell isolation strategy. IJ was responsible for NPM1 diagnostics. HV performed mutational analysis of AML and wrote the manuscript. PAVV produced and analyzed MS data and wrote the manuscript. MHMH developed the T cell isolation and TCR gene transfer strategies, supervised the peptide elution and in vivo experiments, and wrote the manuscript. JHFF conceptualized and supervised the study and wrote the manuscript. MG designed, analyzed, and interpreted all experiments, conceptualized and supervised the study, and wrote the manuscript.

\section{Acknowledgments}

This research was supported by the Dutch Cancer Society (201610222), and the MS work is part of the Investment Grant NWO Medium Programme (project number 91116004), which is (partly) financed by ZonMw (The Netherlands Organisation for Health Research and Development). DIVDL was supported by the MD/ $\mathrm{PhD}$ program and Doelfonds Leukemie from the Bontius Stichting of the Leiden University Medical Center.

Address correspondence to: Dyantha I. van der Lee, Department of Hematology, Leiden University Medical Center, Albinusdreef 2, 2333 ZA Leiden, Netherlands. Phone: 31.71.526.4864; Email: d.i.van_der_lee@lumc.nl.

HMB's present address is: Clinical Trial Center, Erasmus Medical Center, Rotterdam, Netherlands.
1. Döhner H, Weisdorf DJ, Bloomfield CD. Acute myeloid leukemia. N Engl J Med. 2015;373(12):1136-1152.

2. Ferrara F, Schiffer CA. Acute myeloid leukaemia in adults. Lancet. 2013;381(9865):484-495.

3. Cancer Genome Atlas Research Network, et al. Genomic and epigenomic landscapes of adult de novo acute myeloid leukemia. $\mathrm{N}$ Engl J Med. 2013;368(22):2059-2074.

4. Alexandrov LB, et al. Signatures of mutational processes in human cancer. Nature. 2013;500(7463):415-421.

5. Kandoth C, et al. Mutational landscape and significance across 12 major cancer types. Nature. 2013;502(7471):333-339.

6. Papaemmanuil E, et al. Genomic classification and prognosis in acute myeloid leukemia. $N \mathrm{Engl}$ JMed. 2016;374(23):2209-2221.

7. Welch JS, et al. The origin and evolution of mutations in acute myeloid leukemia. Cell.
2012;150(2):264-278.

8. Falini B, et al. Cytoplasmic nucleophosmin in acute myelogenous leukemia with a normal karyotype. N Engl JMed. 2005;352(3):254-266.

9. Coulie PG, Van den Eynde BJ, van der Bruggen P, Boon T. Tumour antigens recognized by $\mathrm{T}$ lymphocytes: at the core of cancer immunotherapy. Nat Rev Cancer. 2014;14(2):135-146.

10. Rosenberg SA, Restifo NP. Adoptive cell transfer as personalized immunotherapy for human cancer. Science. 2015;348(6230):62-68.

11. June $\mathrm{CH}$, Sadelain M. Chimeric antigen receptor therapy. N Engl J Med. 2018;379(1):64-73.

12. Hinrichs CS, Restifo NP. Reassessing target antigens for adoptive T-cell therapy. Nat Biotechnol. 2013;31(11):999-1008.

13. Blankenstein T, Leisegang M, Uckert W, Schreiber H. Targeting cancer-specific mutations by T cell receptor gene therapy. Curr Opin Immunol. 2015;33:112-119.
14. Schumacher TN, Schreiber RD. Neoantigens in cancer immunotherapy. Science. 2015;348(6230):69-74

15. Tran E, Robbins PF, Rosenberg SA. 'Final common pathway' of human cancer immunotherapy: targeting random somatic mutations. Nat Immunol. 2017;18(3):255-262.

16. Verdegaal EM, et al. Neoantigen landscape dynamics during human melanoma-T cell interactions. Nature. 2016;536(7614):91-95.

17. Nielsen M, Andreatta M. NetMHCpan-3.0; improved prediction of binding to $\mathrm{MHC}$ class I molecules integrating information from multiple receptor and peptide length datasets. Genome Med. 2016;8(1):33.

18. Hombrink $\mathrm{P}$, et al. Identification of biological relevant minor histocompatibility antigens within the B-lymphocyte-derived HLA-ligandome using a reverse immunology approach. Clin Cancer Res. 2015;21(9):2177-2186. 
19. Strønen E, et al. Targeting of cancer neoantigens with donor-derived $\mathrm{T}$ cell receptor repertoires. Science. 2016;352(6291):1337-1341.

20. Linnemann C, et al. High-throughput identification of antigen-specific TCRs by TCR gene capture. Nat Med.2013;19(11):1534-1541.

21. Arber DA, et al. The 2016 revision to the World Health Organization classification of myeloid neoplasms and acute leukemia. Blood. 2016;127(20):2391-2405.

22. Pratcorona $\mathrm{M}$, et al. Favorable outcome of patients with acute myeloid leukemia harboring a lowallelic burden FLT3-ITD mutation and concomitant NPM1 mutation: relevance to post-remission therapy. Blood.2013;121(14):2734-2738.

23. Greiner J, et al. Mutated regions of nucleophosmin 1 elicit both CD4(+) and CD8(+) T-cell responses in patients with acute myeloid leukemia. Blood. 2012;120(6):1282-1289.

24. Greiner J, et al. Immune responses against the mutated region of cytoplasmatic NPM1 might contribute to the favorable clinical outcome of AML patients with NPM1 mutations (NPM1mut). Blood. 2013;122(6):1087-1088.

25. Mardiros A, Forman SJ, Budde LE. T cells expressing $\mathrm{CD} 123$ chimeric antigen receptors for treatment of acute myeloid leukemia. Curr Opin Hematol. 2015;22(6):484-488.

26. Gill S, Tasian SK, Ruella M, et al. Preclinical targeting of human acute myeloid leukemia and myeloablation using chimeric antigen receptor-modified T cells. Blood. 2014;123(15):23432354. Blood. 2016;128(21):2585.

27. Amir AL, et al. PRAME-specific allo-HLArestricted T-cells with potent antitumor reactivity useful for therapeutic T-cell receptor gene transfer. Clin Cancer Res. 2011;17(17):5615-5625.

28. Provasi E, et al. Editing T cell specificity towards leukemia by zinc finger nucleases and lentiviral gene transfer. Nat Med. 2012;18(5):807-815.

29. Morris EC, Stauss HJ. Optimizing T-cell receptor gene therapy for hematologic malignancies. Blood. 2016;127(26):3305-3311.

30. Carreno BM, et al. Cancer immunotherapy. A dendritic cell vaccine increases the breadth and diversity of melanoma neoantigen-specific $\mathrm{T}$ cells. Science. 2015;348(6236):803-808.

31. Ott PA, et al. An immunogenic personal neoantigen vaccine for patients with melanoma. Nature. 2017;547(7662):217-221.

32. Sahin U, et al. Personalized RNA mutanome vaccines mobilize poly-specific therapeutic immunity against cancer. Nature. 2017;547(7662):222-226.

33. Xie M, et al. Age-related mutations associated with clonal hematopoietic expansion and malignancies. Nat Med.2014;20(12):1472-1478.

34. Bowman RL, Busque L, Levine RL. Clonal hematopoiesis and evolution to hematopoietic malignancies. Cell Stem Cell. 2018;22(2):157-170.
35. Stone JD, Harris DT, Kranz DM. TCR affinity for $\mathrm{p} / \mathrm{MHC}$ formed by tumor antigens that are self-proteins: impact on efficacy and toxicity. Curr Opin Immunol. 2015;33:16-22.

36. Corthay A, et al. Primary antitumor immune response mediated by $\mathrm{CD} 4+\mathrm{T}$ cells. Immunity. 2005;22(3):371-383.

37. Perez-Diez A, et al. CD4 cells can be more efficient at tumor rejection than CD8 cells. Blood. 2007;109(12):5346-5354.

38. Tran E, et al. Cancer immunotherapy based on mutation-specific CD $4+\mathrm{T}$ cells in a patient with epithelial cancer. Science. 2014;344(6184):641-645.

39. Kreiter S, et al. Mutant MHC class II epitopes drive therapeutic immune responses to cancer. Nature. 2015;520(7549):692-696.

40. Morris EC, Tsallios A, Bendle GM, Xue SA, Stauss $\mathrm{HJ}$. A critical role of T cell antigen receptor-transduced MHC class I-restricted helper T cells in tumor protection. Proc Natl Acad Sci U S A. 2005;102(22):7934-7939.

41. Fujiwara $\mathrm{H}$, et al. Antileukemia multifunctionality of $\mathrm{CD} 4(+) \mathrm{T}$-cells genetically engineered by HLA class I-restricted and WT1-specific T-cell receptor gene transfer. Leukemia. 2015;29(12):2393-2401.

42. Turtle CJ, et al. Immunotherapy of non-Hodgkin's lymphoma with a defined ratio of CD8+ and CD4+CD19-specific chimeric antigen receptor-modified T cells. Sci Transl Med. 2016;8(355):355ra116.

43. Turtle CJ, et al. CD19 CAR-T cells of defined CD4+:CD8+ composition in adult B cell ALL patients. J Clin Invest. 2016;126(6):2123-2138.

44. Busch DH, Fräßle SP, Sommermeyer D, Buchholz VR, Riddell SR. Role of memory T cell subsets for adoptive immunotherapy. Semin Immunol. 2016;28(1):28-34

45. Gattinoni L, Speiser DE, Lichterfeld M, Bonini C. T memory stem cells in health and disease. Nat Med. 2017;23(1):18-27.

46. Beatty GL, Gladney WL. Immune escape mechanisms as a guide for cancer immunotherapy. Clin Cancer Res. 2015;21(4):687-692.

47. Tran E, et al. T-cell transfer therapy targeting mutant KRAS in cancer. $N$ Engl J Med. 2016;375(23):2255-2262.

48. McGranahan N, et al. Allele-specific HLA loss and immune escape in lung cancer evolution. Cell. 2017;171(6):1259-1271.e11.

49. Zaretsky JM, et al. Mutations associated with acquired resistance to PD-1 blockade in melanoma. N Engl J Med. 2016;375(9):819-829.

50. Patel SJ, et al. Identification of essential genes for cancer immunotherapy. Nature. 2017;548(7669):537-542.

51. Manguso RT, et al. In vivo CRISPR screening identifies Ptpn 2 as a cancer immunotherapy tar- get. Nature. 2017;547(7664):413-418.

52. Bendle GM, et al. Lethal graft-versus-host disease in mouse models of $\mathrm{T}$ cell receptor gene therapy. Nat Med. 2010;16(5):565-570.

53. van Loenen MM, et al. Mixed T cell receptor dimers harbor potentially harmful neoreactivity. Proc Natl Acad Sci U S A. 2010;107(24):10972-10977.

54. Kuball J, et al. Facilitating matched pairing and expression of TCR chains introduced into human T cells. Blood. 2007;109(6):2331-2338.

55. Berdien B, Mock U, Atanackovic D, Fehse B. TALEN-mediated editing of endogenous T-cell receptors facilitates efficient reprogramming of $T$ lymphocytes by lentiviral gene transfer. Gene Ther. 2014;21(6):539-548.

56. Mastaglio S, et al. NY-ESO-1 TCR single edited stem and central memory $\mathrm{T}$ cells to treat multiple myeloma without graft-versus-host disease. Blood. 2017;130(5):606-618.

57. Roth TL, et al. Reprogramming human T cell function and specificity with non-viral genome targeting. Nature. 2018;559(7714):405-409.

58. Ivey A, et al. Assessment of minimal residual disease in standard-risk AML. $N$ Engl J Med. 2016;374(5):422-433.

59. Kremer AN, et al. Endogenous HLA class II epitopes that are immunogenic in vivo show distinc behavior toward HLA-DM and its natural inhibitor HLA-DO. Blood. 2012;120(16):3246-3255.

60. Hassan C, et al. The human leukocyte antigenpresented ligandome of B lymphocytes. Mol Cell Proteomics. 2013;12(7):1829-1843.

61. Meiring HD, van der Heeft E, ten Hove GJ, de Jong APJM. Nanoscale LC-MS(n): technical design and applications to peptide and protein analysis. J Sep Sci. 2002;25(9):557-568.

62. Burrows SR, Kienzle N, Winterhalter A, Bharadwaj M, Altman JD, Brooks A. Peptide-MHC class I tetrameric complexes display exquisite ligand specificity. JImmunol. 2000;165(11):6229-6234.

63. Rodenko B, et al. Generation of peptide-MHC class I complexes through UV-mediated ligand exchange. Nat Protoc. 2006;1(3):1120-1132.

64. Jahn L, et al. TCR-based therapy for multiple myeloma and other $\mathrm{B}$-cell malignancies targeting intracellular transcription factor BOB1. Blood. 2017;129(10):1284-1295.

65. van Bergen CA, et al. Selective graft-versusleukemia depends on magnitude and diversity of the alloreactive $\mathrm{T}$ cell response. J Clin Invest. 2017;127(2):517-529.

66. Koning MT, et al. ARTISAN PCR: rapid identification of full-length immunoglobulin rearrangements without primer binding bias. Br J Haematol. 2017;178(6):983-986.

67. Lefranc MP, et al. IMGT, the international ImMunoGeneTics database. Nucleic Acids Res. 1999;27(1):209-212. 